\title{
Contribuição para o aprimoramento de projeto, construção e operação de reatores UASB aplicados ao tratamento de esgoto sanitário - Parte 3: Gerenciamento de lodo e escuma
}

\section{Contribution for improving the design, construction and operation of UASB reactors treating sewage - Part 3: Management of sludge and scum}

Lívia Cristina da Silva Lobato / Thiago Bressani Ribeiro / Bruno Sidnei da Silva / Carlos Andrés Días Flórez / Priscilla Natalie Pereira Neves/ Carlos Augusto de Lemos Chernicharo (*)

DOI: 10.4322/dae.2018.040

\section{Resumo}

A ausência e/ou a não efetividade de rotinas operacionais adequadas para o descarte de lodo excedente e remoção de escuma tem resultado em graves problemas operacionais e de perda de eficiência do sistema de tratamento como um todo. A fim de garantir o adequado gerenciamento desses subprodutos sólidos, é imprescindível o estabelecimento de rotinas operacionais para o manejo do lodo e da escuma, que possam ser implementadas de forma efetiva nos reatores UASB. Esta Nota Técnica (NT) tem como objetivo apresentar os problemas e suas respectivas origens relacionados ao gerenciamento inadequado desses subprodutos sólidos, bem como os possíveis aprimoramentos de projeto, construção e operação. Em síntese, os aprimoramentos referem-se aos seguintes aspectos principais: i) sensibilização dos usuários; ii) melhorias no tratamento preliminar; iii) cálculo mais preciso da produção de lodo nos reatores, levando em consideração o recebimento de todas as possíveis contribuições à ETE; iv) definição das quantidades de lodo a serem mantidas e a serem descartadas do reator; v) definição da estratégia de descarte e das características do sistema de desaguamento; vi) controle sobre o recebimento de efluentes não domésticos; vii) melhor controle sobre a formação de escuma no compartimento de decantação; e viii) utilização de separadores trifásicos equipados com dispositivo de remoção de escuma. Importante ressaltar que o gerenciamento integrado dos subprodutos sólidos (lodo e escuma), bem como do biogás, pode trazer importantes benefícios para as ETEs. Palavras-chave: Biogás; desaguamento; óleos e graxas; reatores anaeróbios; separador trifásico; tratamento preliminar.

\footnotetext{
Lívia Cristina da Silva Lobato - Engenheira Civil pela UFMG. Doutora em Saneamento, Meio Ambiente e Recursos Hídricos pela UFMG. Membro do INCT ETEs Sustentáveis.

Thiago Bressani Ribeiro - Engenheiro Ambiental pela Universidade FUMEC. Mestre em Saneamento, Meio Ambiente e Recursos Hídricos pela UFMG. Doutorando em Saneamento pelas Universidades de Ghent (Bélgica) e UFMG. Membro do INCT ETEs Sustentáveis.

Bruno Sidnei da Silva - Engenheiro Ambiental pela UFSC. Mestre em Engenharia Hidráulica e Ambiental pela USP. Engenheiro da Companhia de Saneamento do Estado de São Paulo (Sabesp).

Carlos Andrés Días Flórez - Engenheiro Civil pela Universidade de Antióquia. Mestre em Saneamento, Meio Ambiente e Recursos Hídricos pela UFMG. Priscilla Natalie Pereira Neves - Engenheira Ambiental pela UFMG. Mestranda em Saneamento, Meio Ambiente e Recursos Hídricos pela UFMG. Carlos Augusto de Lemos Chernicharo - Engenheiro Civil pela UFMG. Doutor em Engenharia Ambiental pela Universidade de Newcastle upon Tyne - UK. Professor titular do Departamento de Engenharia Sanitária e Ambiental da UFMG. Coordenador do INCT ETEs Sustentáveis.

*Endereço para correspondência: Avenida Antônio Carlos 6.627 - Universidade Federal de Minas Gerais - Escola de Engenharia - Departamento de Engenharia Sanitária e Ambiental - Bloco 1. Belo Horizonte, MG. CEP: 31270-901. e-mail: calemosadesa.ufmg.br
} 


\section{Abstract}

The absence and/or the non-effectiveness of suitable operational routines for the withdrawal of excess sludge and scum removal have resulted in serious operational problems and loss of efficiency of the sewage treatment system as a whole. In order to ensure the adequate management of these solid by-products, it is essential to establish operational routines for sludge and scum management that can be effectively implemented in UASB reactors. This Technical Note (TN) aims to present the problems and their respective origins related to the inadequate management of these solid by-products, as well as the possible improvements of design, construction and operation. In summary, the improvements refer to the following main aspects: i) users awareness; ii) improvements to the preliminary treatment; iii) more accurate calculation of the sludge production, taking into account the receipt of all possible contributions to the STP; iv) definition of the quantities of sludge to be maintained and to be discharged from the reactor; v) definition of the disposal strategy and the characteristics of the dewatering system; vi) control over the reception of non-domestic effluents; vii) better control over the formation of scum in the sedimentation compartment; and viii) use of three-phase separators equipped with a scum removal system. It is important to emphasize that the integrated management of solid by-products (sludge and scum), as well as biogas, can bring important benefits to STPs. Keywords: Anaerobic reactors; biogas; dewatering; oil and grease; preliminary treatment; three-phase separator.

\section{INTRODUÇÃO}

O tratamento de esgoto sanitário em reatores UASB gera subprodutos sólidos - lodo e escuma, os quais precisam ser adequadamente gerenciados a fim de garantir a eficiência e as vantagens desse tipo de tecnologia. Entretanto, em grande parte das estações de tratamento de esgoto (ETE) no Brasil, esse gerenciamento muitas vezes é negligenciado, acarretando em diversos problemas para o sistema de tratamento.

Durante a partida do sistema de tratamento, a acumulação de lodo (biomassa + sólidos inertes) nos reatores UASB acontece após alguns meses de operação contínua, sendo que a taxa de acumulação depende tanto do crescimento da biomassa (síntese de células microbianas) como também da presença de sólidos em suspensão inertes ou não biodegradáveis. Esses últimos, embora não façam parte da biomassa propriamente dita, responsável pela degradação dos compostos orgânicos que adentram ao reator, podem contribuir de maneira significativa para a majoração do coeficiente de produção de lodo, devendo, portanto, serem necessariamente computados nos cálculos de produção de lodo dos reatores anaeróbios utilizados para o tratamento de esgoto sanitário.

Uma das principais características dos reatores UASB, quando operados adequadamente, é a sua elevada capacidade de retenção de lodo, resultando em idades de lodo elevadas e conferindo elevado grau de estabilização do lodo. Essa elevada capacidade de retenção do lodo é decorrente da existência do separador trifásico, das velocidades ascensionais impostas ao reator e da alta sedimentabilidade do tipo de lodo desenvolvido neste sistema (LEITÃo et al., 2009). Entretanto, o reator, dado o seu volume compacto, apresenta uma capacidade limite de retenção e armazenamento de lodo, ditada principalmente pelos volumes dos compartimentos de digestão e de decantação do reator. Estas capacidades não devem ser ultrapassadas, em função de estratégias de descarte de lodo inexistentes ou inadequadas; caso contrário poderá ocorrer perda excessiva de sólidos e deterioração da qualidade do 
efluente do reator, além de outros problemas correlatos, conforme descrito na Parte 1 desta Coletânea de NTs (CHERNICHARO et al., 2018). Nesse sentido, é mandatório que o lodo presente em excesso seja removido periodicamente e de forma apropriada.

Em relação a escuma no interior dos reatores UASB, sua formação, acumulação e tipo dependem essencialmente da composição do esgoto bruto, particularmente no que tange à presença de detritos (p. ex.: cabelo, cotonete, absorvente, fio dental, algodão, lenço umedecido, ponta de cigarro, materiais plásticos) e óleos e graxas. Assim como o lodo, a escuma também deve ser removida com a frequência devida, visto que seu acúmulo pode levar ao bloqueio da passagem natural do gás, prejudicando sua coleta (LETTINGA e HULSHOFF POL, 1991), bem como pode ocasionar a diminuição da eficiência do tratamento, devido à perda de partículas de escuma juntamente com o efluente final (SATO et al., 2006), dentre outros problemas igualmente graves, conforme descritos na Parte 1 desta Coletânea de NTs (CHERNICHARO et al. 2018) e detalhados mais adiante nesta NT.

A ausência e/ou a não efetividade do gerenciamento do lodo e da escuma pode comprometer a eficiência do sistema de tratamento como um todo. Assim, é imperiosa a necessidade de aprimoramentos no projeto e na construção dos reatores UASB, bem como de estabelecimento de rotinas operacionais adequadas para o gerenciamento desses subprodutos, que possam ser implementadas de forma efetiva nesses reatores.

\section{ORIGEM E PROBLEMAS RELACIONADOS AO LODO EXCEDENTE}

Diversos reatores UASB existentes no Brasil operam com quantidades de lodos que ultrapassam suas capacidades de retenção e armazenamento. Como consequência principal, esses reatores, via de regra, apresentam perda excessiva de sólidos, que impactam negativamente a qualidade do efluente e a eficiência física de remoção de material particulado, em decorrência do esgotamento da capacidade de retenção e armazenamento de lodo no interior do reator. Adicionalmente, a perda de sólidos com o efluente dos reatores UASB pode acarretar sobrecarga nas unidades de pós-tratamento, a exemplo da colmatação do meio suporte de filtros biológicos percoladores (FBP) (Figura 1). Também, o envio de lodo aeróbio da unidade de pós-tratamento (p. ex.: FBP, lodos ativados), para adensamento e estabilização nos reatores UASB, tem sido apontado como uma das causas da perda de sólidos no efluente desses reatores. Entretanto, experiências práticas indicaram que o estabelecimento e implementação de protocolos operacionais para o envio desse lodo aos reatores UASB e para os descartes de lodo excedente dessas unidades, de forma sistematizada e com frequência adequada, fazem frente às dificuldades relatadas no gerenciamento do lodo secundário aeróbio gerado na unidade de pós-tratamento. Essa questão é abordada em detalhes na Parte 6 desta Coletânea de NTs (ALMEIDA et al., 2018). 

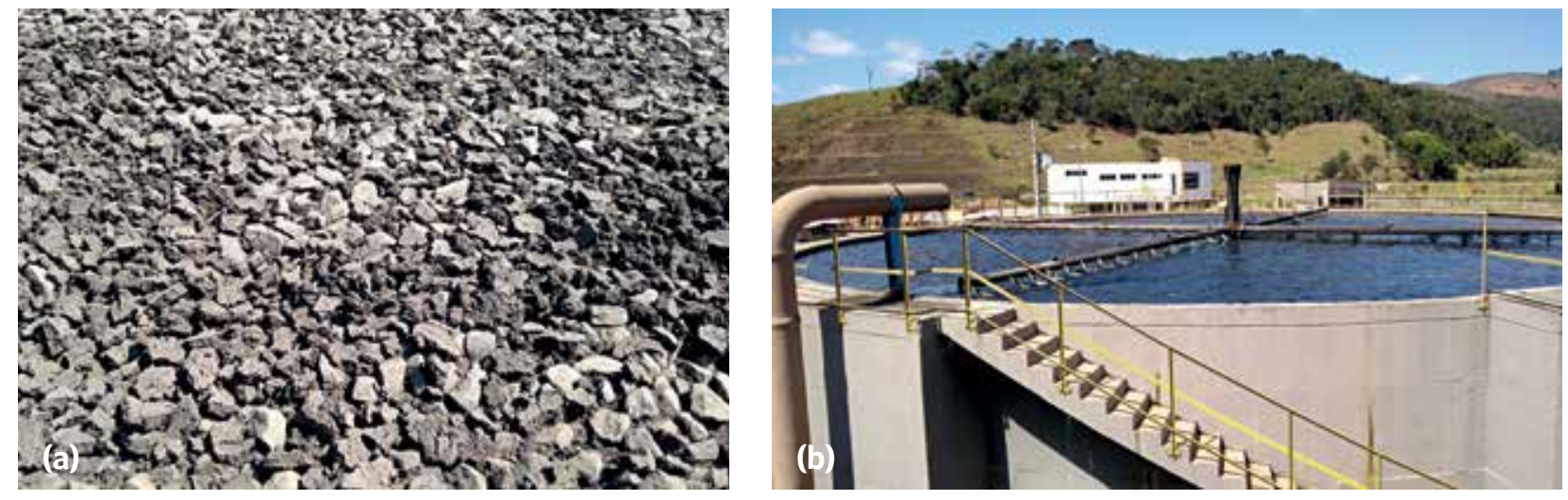

Figura 1 - Impacto da perda excessiva de sólidos sobre a unidade de pós-tratamento: a) colmatação do meio suporte;

b) afogamento de filtros biológicos percoladores pós-reatores UASB.

Um ponto que merece destaque por aumentar a produção de lodo e, consequentemente, impactar o seu gerenciamento, refere-se ao recebimento, na ETE, de contribuições não consideradas na etapa de projeto (p. ex.: lodo de tanques sépticos, lixiviado de aterros sanitários, lodo químico de estações de tratamento de água - ETA, efluentes não domésticos - END). Especificamente em relação ao lodo de ETA, a Figura 2 ilustra o aspecto do lodo químico oriundo da limpeza de floculadores e decantadores, quando úmido (Figura 2a) e após desaguamento (Figura 2b). Percebe-se, claramente, o aspecto "barrento" do lodo, constituído basicamente por silte e argila. Já na Figura 2c é apresentado o impacto do lançamento do lodo de ETA na rede coletora de esgoto, podendo-se observar o aumento expressivo, em cerca de 15 vezes, do teor de sólidos sedimentáveis no esgoto que chega à ETE.
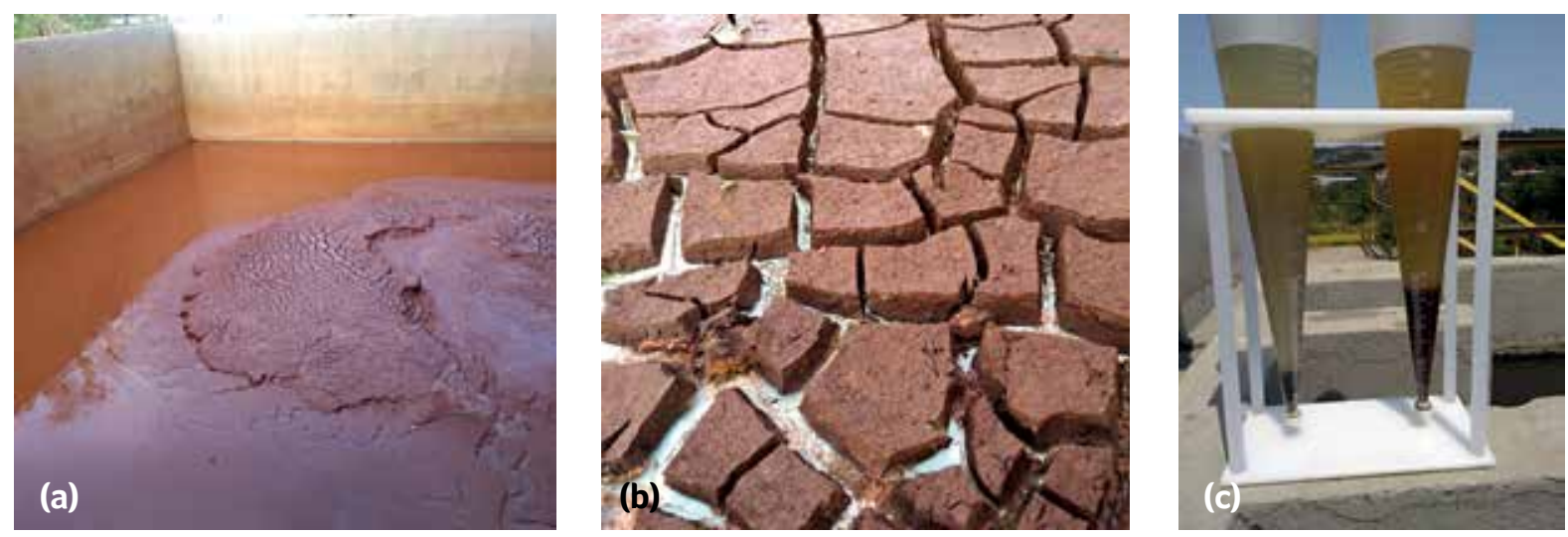

Figura 2 - Lodo químico de uma ETA: (a) retido em tanque pulmão após o descarte de floculadores e decantadores; (b) após etapa de desaguamento; (c) impacto sobre o teor de sólidos sedimentáveis no esgoto afluente a uma ETE (cone à esquerda: apenas esgoto bruto - cerca de $5 \mathrm{~mL} . \mathrm{L}^{-1}$; cone à direita: esgoto bruto + lodo químico da ETA descartado na rede de esgoto - cerca de $\left.80 \mathrm{~mL} \cdot \mathrm{L}^{-1}\right)$. 
Estudos sobre a produção de lodo em uma ETE em escala plena, na qual os reatores UASB foram originalmente projetados para tratar apenas esgoto sanitário e o lodo secundário aeróbio gerado na unidade de pós-tratamento, mostraram que o coeficiente real de produção de lodo $\left(\mathrm{Y}_{\text {lodo }}\right)$ era cerca de $20 \%$ superior ao valor considerado no projeto. Ao se investigar a razão da discrepância entre o $Y_{\text {lodo }}$ de projeto e o $Y_{\text {lodo }}$ de campo, identificou-se que a ETE recebia contribuições não consideradas no projeto, relativas ao recebimento de lixiviado de aterro sanitário, de lodo de tanque séptico e de lodo químico de uma estação de tratamento de águas fluviais. Ou seja, decisões tomadas no nível de gerência não levaram em consideração se o sistema de desaguamento da ETE em questão possuía capacidade para processar a quantidade adicional de lodo que seria gerada nos reatores UASB.

Normalmente, a ausência de uma rotina operacional para os descartes sistemáticos de lodo dos reatores UASB, ou até mesmo a sua ineficácia, está associada a um ou mais dos seguintes fatores:

- Pontos de amostragem, utilizados para o monitoramento da concentração do lodo ao longo do compartimento de digestão do reator, em número insuficiente e/ou instalados em posição errada, em desacordo com o projeto (Figura 3).

- Tubulações de descarte de lodo em número insuficiente ou mal distribuídas ao longo da altura do compartimento de digestão (Figura 4).
- Manuais e/ou diretrizes de operação dos reatores UASB e dos sistemas de desaguamento que não detalham adequadamente os procedimentos a serem seguidos pelos operadores.

- Falta de remoção sistemática de lodo dos reatores UASB e dos leitos de secagem em decorrência de problemas logísticos e administrativos ( $p$. ex.: contrato de prestação de serviço referente ao transporte do lodo não compatível com a frequência necessária, impedindo o descarte de lodo do reator).

- Falhas nos projetos dos sistemas de desaguamento natural ou mecanizado, dimensionados com capacidade aquém da necessidade de processamento de lodo na ETE ou incompatíveis com as características do lodo a ser desaguado, por não levar em consideração as especificidades locais, as condições climáticas e operacionais ( $p$. ex.: escala dos operadores, transporte do lodo, disponibilidade de produtos químicos e peças de reposição, necessidade de manutenções preventivas, possibilidade de paralisações devido à necessidade de manutenções corretivas).

- Equipamentos do sistema de desaguamento mecanizado (p. ex.: bombas de lodo, dosadores de polímero, centrífugas) fora de operação, em decorrência de dificuldades com a manutenção preventiva e corretiva dos mesmos. 


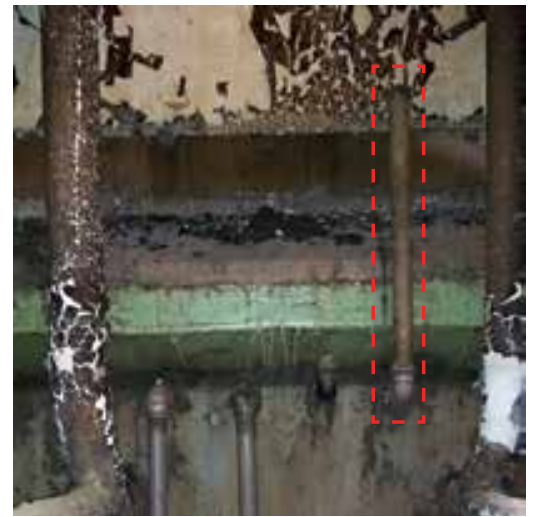

Figura 3 - Instalação de ponto de amostragem de lodo bem acima do limite do compartimento de decantação, em desacordo com o projeto.

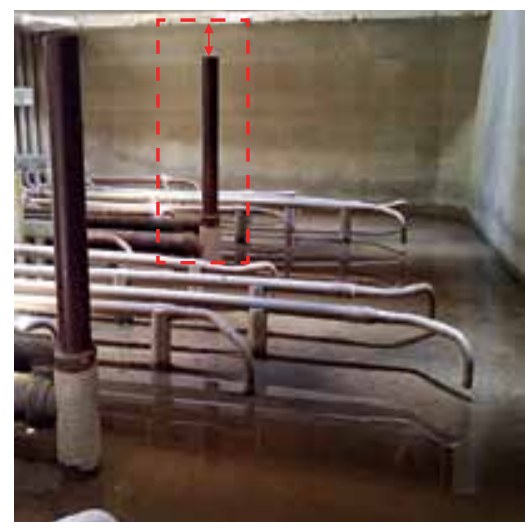

Figura 4 - Tubulação de descarte de lodo posicionada muito próxima do defletor de gases, em desacordo com o projeto.
Além dos problemas relacionados ao gerenciamento do lodo propriamente dito, conforme abordado anteriormente, existem ainda problemas que são ocasionados pelo funcionamento inadequado das unidades que compõem o tratamento preliminar, sendo comum a passagem de elevada quantidade de detritos (lixo). Os detritos com maior densidade e, em alguns casos a areia, irão se depositar no fundo dos reatores e passarão a fazer parte do lodo. A agregação de detritos e areia ao lodo pode resultar na diminuição do volume útil dos reatores e, quando removidos, podem causar entupimentos nas tubulações de lodo e prejudicar o funcionamento do sistema de desaguamento. Ademais, resultará na geração de um subproduto sólido (lodo desaguado) com qualidade estética desagradável. Na Figura 5 são apresentadas imagens que ilustram detritos retidos em uma peneira de $6 \mathrm{~mm}$ (Figura $5 \mathrm{a}$ ) e detritos que adentraram o reator e passaram a fazer parte do lodo descartado e desaguado em leitos de secagem (Figura 5b).
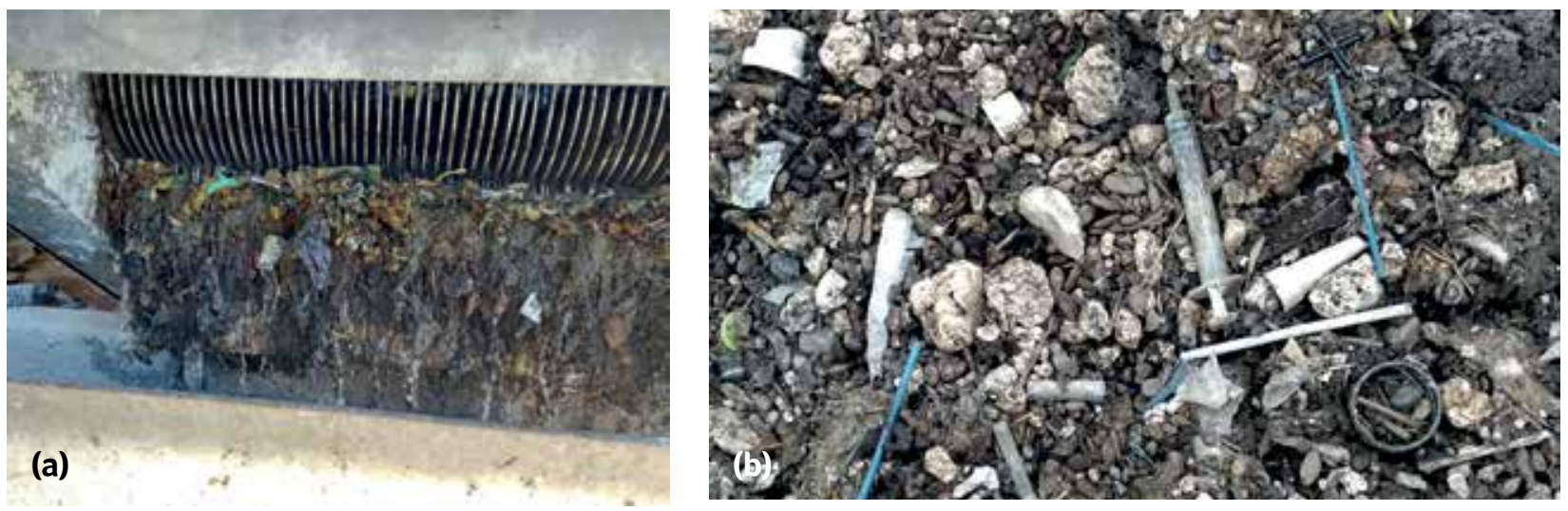

Figura 5 - a) Detritos retidos em uma unidade de peneiramento de $6 \mathrm{~mm}$; b) Presença de detritos em lodo e escuma desaguados em leitos de secagem. 


\section{POSSIVEIS APRIMORAMENTOS}

\section{RELACIONADOS AO GERENCIAMENTO DO LODO}

Face ao exposto anteriormente, depreende-se que é de fundamental importância o correto gerenciamento do lodo produzido nos reatores UASB e na ETE como um todo. A adoção das medidas descritas a seguir pode contribuir significativamente para o melhor gerenciamento do lodo e solução de diversos problemas que ocorrem atualmente em ETEs que empregam reatores UASB para o tratamento de esgoto sanitário.

\subsection{Sensibilização de usuários}

Vários dos atuais problemas operacionais nas ETEs brasileiras decorrem da inadequada utilização das instalações sanitárias no interior das residências (e também de estabelecimentos comerciais - p. ex.: restaurantes), o que resulta na alteração significativa dos esgotos gerados, em termos quantitativos e qualitativos, como, presença excessiva de água de chuva, de detergente (surfactantes), de óleo de cozinha e de detritos ( $p$. ex.: cabelo, cotonete, absorvente, fio dental, algodão, lenço umedecido, ponta de cigarro, materiais plásticos). Assim, a sensibilização dos usuários dos serviços de esgotamento sanitário passa a ser uma ação essencial. Para tanto, é necessário a criação de espaços dialógicos, onde seja possível apreender o conhecimento, a percepção e as perspectivas da população em relação à importância do saneamento na comunidade, em particular sobre a geração e as soluções de tratamento e destinação que são dadas ao esgoto sanitário. Ademais, nesses espaços, é importante a realização de debates sobre como cada usuário é diretamente responsável pelo processo na sua origem, a partir do que entende como razoável lançar nas peças sanitárias.

\subsection{Melhoria no tratamento preliminar}

Com o intuito de reduzir a entrada de detritos e de areia nos reatores UASB, é de extrema importância um maior cuidado na definição das unidades do tratamento preliminar, visto que boa parcela desses sólidos poderia deixar de fazer parte da composição do lodo (e de constituir a camada de escuma), se as unidades do tratamento preliminar fossem capazes de reter estes materiais. Dentre as melhorias preconizadas, pode-se mencionar a utilização de grades ultrafinas e de peneiras de pequena abertura ( 3 a $4 \mathrm{~mm}$ ). Complementarmente, outra possível melhoria estaria associada à remoção de óleos e graxas a montante dos reatores UASB, no tratamento preliminar. Uma alternativa que vem sendo implantada em algumas ETEs que empregam reatores anaeróbios são os desarenadores aerados (fluxo em espiral), conforme relatado na Parte 2 desta Coletânea de NTs (BRESSANI-RIBEIRO et al., 2018). No entanto, as esparsas experiências brasileiras reportadas na literatura indicam baixa eficiência desses equipamentos associada à remoção de óleos e graxas.

\subsection{Cálculo mais preciso da produção de lodo nos reatores UASB}

Usualmente, as estimativas da produção de lodo são realizadas a partir da faixa reportada na literatura para o coeficiente de produção de lodo $\left(\mathrm{Y}_{\text {lodo }}\right)$, o qual varia de 0,10 a 0,20 kgST.kgDQO- ${ }^{-1}$. Entretanto, essa faixa de valores refere-se apenas à produção de lodo em um reator UASB aplicado exclusivamente ao tratamento de esgoto doméstico. Nos casos em que o reator recebe outros tipos de contribuições (p. ex.: lodo aeróbio produzido na unidade de pós-tratamento, lodo de tanque séptico, lixiviado de aterro sanitário, efluentes não domésticos), o valor de $Y_{\text {lodo }}$ será obviamente mais elevado. Torna-se, portanto, imprescindível que o projeto defina o valor de $Y_{\text {lodo }}$ com a máxima segurança possível, uma vez que o 
mesmo impactará diretamente: i) a produção de lodo do reator; ii) o dimensionamento do sistema de desaguamento; e iii) o estabelecimento das rotinas operacionais de descarte de lodo.

No caso da previsão de recebimento de lodo de tanque séptico em reatores UASB, é necessária a avaliação rigorosa dos volumes esperados e da possibilidade de implementar unidade específica para o recebimento desse tipo de contribuição, que permita a separação e envio do sobrenadante para o reator, e o lodo adensado para um digestor complementar ou, se estiver bem estabilizado, diretamente para a unidade de desaguamento.

No tocante ao recebimento de lixiviado de aterro sanitário e de efluentes não domésticos (END) nos reatores UASB, deve-se atentar para as seguintes questões principais:

- Lixiviados de aterros jovens (usualmente com menos de 5 anos de operação) apresentam concentrações bastante elevadas dos parâmetros demanda bioquímica de oxigênio (DBO), demanda química de oxigênio (DQO), sulfetos e amônia, de tal sorte que eventuais impactos sobre a estabilidade e o desempenho do reator vão depender intrinsicamente do grau de diluição do lixiviado em relação à vazão de esgoto afluente à ETE. Concentrações mais elevadas de DBO e de DQQO na mistura esgoto bruto + lixiviado contribuem diretamente para o aumento da produção de lodo no reator, todavia também possibilitam o incremento da produção de biogás, de interesse nos casos em que se pratica o aproveitamento energético deste subproduto. Por sua vez, concentrações elevadas de sulfetos e amônia na mistura esgoto bruto + lixiviado poderiam, eventualmente, causar toxicidade aos microrganismos anaeróbios, notadamente às arqueias metanogênicas. Para que não haja riscos de toxicidade, é importante verificar (e garantir) que o fator de diluição seja elevado, para que as concentrações de sulfetos e de amônia na mistura esgoto bruto + lixiviado resultem em va- lores bem abaixo dos níveis considerados tóxicos (CHERNICHARO, 2007).

- Lixiviados de aterros antigos (normalmente com mais de 5 anos de operação) tendem a apresentar elevadas relações DQQO/DBO (pouca matéria orgânica biodegradável), de tal sorte que pouco contribuem para o aumento da produção de lodo e de biogás no reator. Ademais, as concentrações de sulfetos, amônia e compostos recalcitrantes são tipicamente elevadas, sendo que eventuais problemas de toxicidade continuam a depender dos fatores de diluição desses constituintes, conforme abordado anteriormente.

- Quanto aos ENDs, a aptidão do reator anaeróbio em tratá-los conjuntamente com o esgoto doméstico depende intrinsicamente do tipo de END em questão. ENDs de natureza essencialmente orgânica e com baixas concentrações de sólidos suspensos (p. ex.: efluentes de cervejarias, fábricas de refrigerantes) usualmente podem ser recebidos sem maiores problemas, devendo o projetista atentar principalmente para os aspectos de maior produção de lodo (mas também de biogás) e de riscos de acidificação do reator, caso a alcalinidade do esgoto não seja suficiente para a neutralização dos ácidos orgânicos formados a partir desses ENDs (que se acidificam muito rapidamente). Para outros tipos de ENDs de natureza orgânica, deve-se proceder análise ainda mais criteriosa, com atenção especial para a presença de elevadas concentrações de sólidos suspensos e de elementos potencialmente tóxicos (p. ex.: sulfetos, amônia, metais pesados). ENDs de natureza inorgânica (p. ex.: galvanoplastia) não devem ser encaminhados para tratamento em ETEs que empregam processos biológicos. Complementarmente, seria desejável que as ETEs dispusessem, minimamente, de sensores para medição online de $\mathrm{pH}$ junto à chegada do esgoto bruto, a fim de possibilitar a identificação de mudanças bruscas nos valores desse parâmetro. Muito embora ações de remediação sejam difíceis quando da detecção 
de valores de $\mathrm{pH}$ fora da faixa usual do esgoto $(6,5$ a 7,5), o registro das medições poderia auxiliar na identificação da origem do problema e na definição das medidas a serem tomadas.

Em relação ao lodo químico de ETA, este não deve ser encaminhado para reatores UASB, visto que suas características podem prejudicar o funcionamento e a eficiência do reator. O lodo resultante da limpeza de floculadores e decantadores, apresenta, via de regra, elevado teor de sólidos inorgânicos - 0,5 a 1,0\% (notadamente silte e argila) e, se lançado na rede de coleta e transporte de esgoto sanitário, muito provavelmente irá se acumular no fundo dos reatores, reduzindo o volume útil dos mesmos. Ademais, esses sólidos são de difícil remoção pelo sistema de extração de lodo utilizado nos reatores UASB. Caso seja considerada a possibilidade de encaminhamento de lodo químico de ETA para ETEs com reatores UASB, deverá ser realizado estudo técnico criterioso que possibilite atestar que os elementos contidos no lodo químico não ocasionarão a formação de bancos de sedimentos no fundo do reator. Há que se considerar, ainda, eventuais riscos de danos a bombas e outros equipamentos (p. ex.: centrífugas). O recebimento do lodo químico de ETA em ETE também pode gerar impactos na atividade microbiana. Ao avaliar os efeitos do recebimento de lodo de ETA (com utilização de sulfato de alumínio como coagulante) nos de- cantadores primários de uma ETE, Scalize (2003) observou, a partir de testes de atividade metanogênica, uma maior produção de metano no frasco controle (que não continha lodo de ETA) e uma decrescente produção de metano à medida que se aumentou a fração de lodo de ETA nos frascos. Ademais, espécies de microrganismos do gênero Methanothrix sp foram inibidas, sendo encontradas em maior número no frasco controle e em menor quantidade nos frascos em que foi adicionado lodo de ETA, sendo possível inferir que esse lodo foi tóxico aos microrganismos metanogênicos, podendo prejudicar o processo de digestão anaeróbia.

\subsection{Previsão de adequado sistema de amostragem de lodo ao longo da altura do reator}

Para o estabelecimento das estratégias de descarte (quantidade e frequência) é necessário o monitoramento contínuo do lodo presente no reator, a partir da determinação do perfil e da massa de sólidos (CHERNICHARO, 2007). Para tanto, é essencial que o reator disponha de um sistema de amostragem que permita a adequada identificação da altura e da concentração do lodo no interior do compartimento de digestão, devendo assim apresentar as características principais descritas no Quadro 1 e exemplificadas na Figura 6.

Quadro 1 - Principais diretrizes para projeto e construção do sistema de amostragem de lodo

\footnotetext{
- Previsão de pontos verticais de amostragem de lodo ao longo de toda a altura do compartimento de digestão do reator, distantes no máximo 0,50 m entre si, sendo o primeiro ponto na mesma altura do descarte de fundo $(0,20$ a 0,30 m) e o último na interface dos compartimentos de digestão e de decantação. Os demais pontos de amostragem devem ser distribuídos equitativamente entre o primeiro e o último ponto de amostragem, sendo o ideal um mínimo de 4 pontos de amostragem (Figura 6a).

- Previsão de caixa de manobra dos registros de amostragem de lodo que possibilite o adequado trabalho do operador, atentando para a necessidade de manuseio dos frascos de coleta e de limpeza das instalações (Figura 6b).

- Os registros deverão ser do tipo esfera, sendo recomendada a utilização de registro metálico seguido de registro de PVC em todos os pontos de amostragem de lodo (Figura 6c e 6d)

- Devem ser previstos conjuntos de pontos verticais de amostragem que possibilitem a caracterização representativa do lodo de todo o volume reacional do compartimento de digestão do reator.

-As tubulações e registros de amostragem devem possuir diâmetro interno útil mínimo de 50 mm.
} 

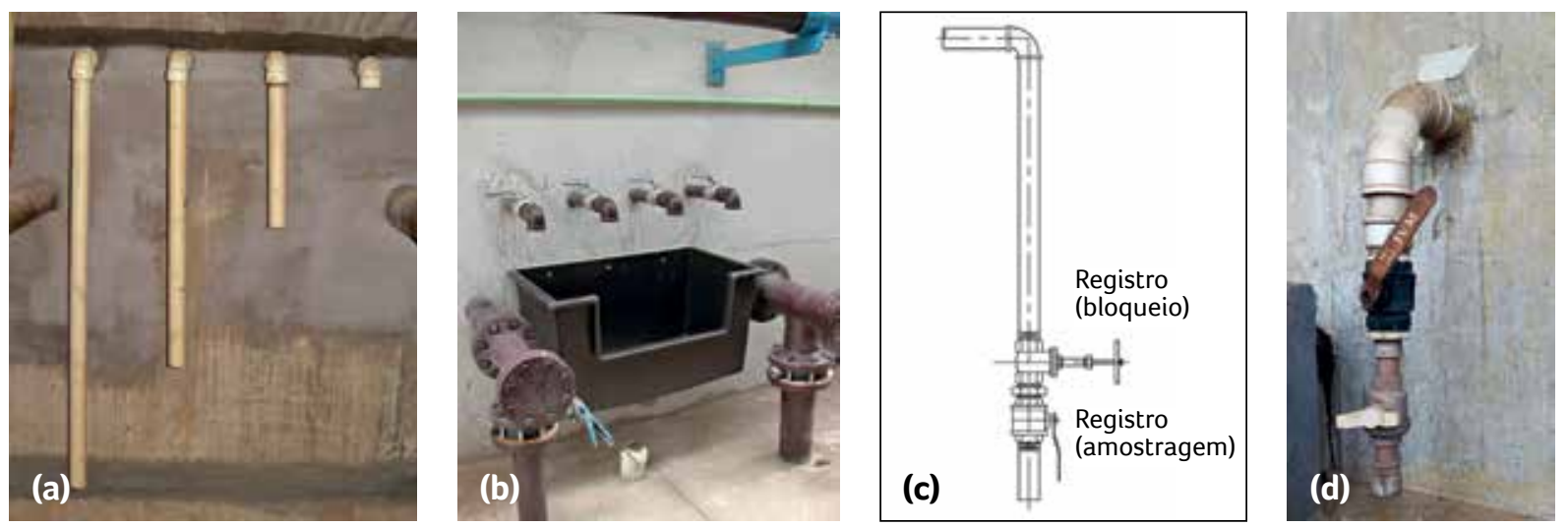

Figura 6 - Sistema de amostragem de lodo de reator UASB: a) vista interna dos pontos verticais de amostragem no interior do compartimento de digestão, espaçados em $50 \mathrm{~cm}$; b) vista externa dos pontos de amostragem e da caixa de manobra dos registros; c) e d) detalhe do registro metálico seguido de registro de PVC.

\subsection{Previsão de adequado sistema de descarte de lodo dos reatores}

De forma a propiciar maior flexibilidade operacional, recomenda-se a previsão de conjuntos de tubulações de descarte de lodo em duas profundidades diferentes no interior do compartimento de digestão do reator: um conjunto inferior, localizado entre 0,20 e 0,30 m acima do fundo do reator; e um conjunto superior, localizado entre 1,00 e 1,50 m acima do fundo do reator. $O$ conjunto inferior de tubulações permite o descarte do lodo mais concentrado, que apresenta melhores condições de sedimentabilidade, enquanto o conjunto superior permite a retirada do lodo menos concentrado, com piores condições de sedimentabilidade (Figura 7). Essa configuração de sistema de descarte (superior e inferior) busca possibilitar que seja feita a remoção programada do lodo de pior qualidade (superior, menos concentrado) e a preservação do lodo de melhor qualidade (inferior, mais concentrado), de modo a proporcionar: i) a obtenção de uma maior idade do lodo e, consequentemente, o descarte de um lodo mais estabilizado; ii) a manutenção de leito de lodo denso junto ao fundo do reator, que possa atuar como um "filtro" que auxilie na retenção de sólidos suspensos por tempo suficiente para que possam ser hidrolisados; e iii) menor perda de sólidos para o compartimento de decantação, refletindo diretamente na melhoria da qualidade do efluente do reator. Ademais, a parcela de lodo descartada pelo fundo possibilita a remoção parcial de sólidos inertes (areia) que adentraram ao reator. $O$ sistema de descarte de lodo deve apresentar as características principais descritas no Quadro 2 e exemplificadas na Figura 7.

Quadro 2 - Principais diretrizes para projeto e construção do sistema de descarte de lodo

\footnotetext{
- Previsão de conjuntos de tubulações de descarte de lodo em duas diferentes alturas do compartimento de digestão do reator: tubulações inferiores localizadas entre 0,20 e 0,30 m do fundo; e tubulações superiores localizadas entre 1,00 e 1,50 m do fundo. Atentar que as tubulações superiores de descarte de lodo devem ficar posicionadas a pelo menos $0,50 \mathrm{~m}$ abaixo do defletor de gases, de modo a possibilitar a remoção efetiva do lodo menos concentrado (Figura 7a e 7b). De acordo com a NBR 12.209, a tubulação superior de descarte de lodo deve ser posicionada a pelo menos 1,00 m abaixo da entrada do compartimento de decantação (ABNT, 2011) (Figura 7a).

- Previsão de uma tubulação de descarte de lodo de fundo para cada 20 a $30 \mathrm{~m}^{2}$ de área de reator. Para o descarte de lodo superior, menos concentrado, podem ser utilizadas áreas de influência mais elevadas $\left(30\right.$ a $\left.50 \mathrm{~m}^{2}\right)$, ou avaliada a possibilidade de utilização de uma única tubulação, de grande diâmetro, interligada a ramais coletores, de 100 ou $150 \mathrm{~mm}$. A tubulação de grande diâmetro deve ser dimensionada com vistas a se alcançar perda de carga próxima à zero, considerando a vazão total decorrente do somatório dos ramais coletores a ela interligados.

- As tubulações e válvulas de descarte do lodo inferior devem possuir diâmetro interno útil mínimo de 150 mm. Para as tubulações e válvulas de descarte do lodo superior pode ser adotado o diâmetro interno de $100 \mathrm{~mm}$. As válvulas de manobra devem ser, preferencialmente, do tipo faca.
} 

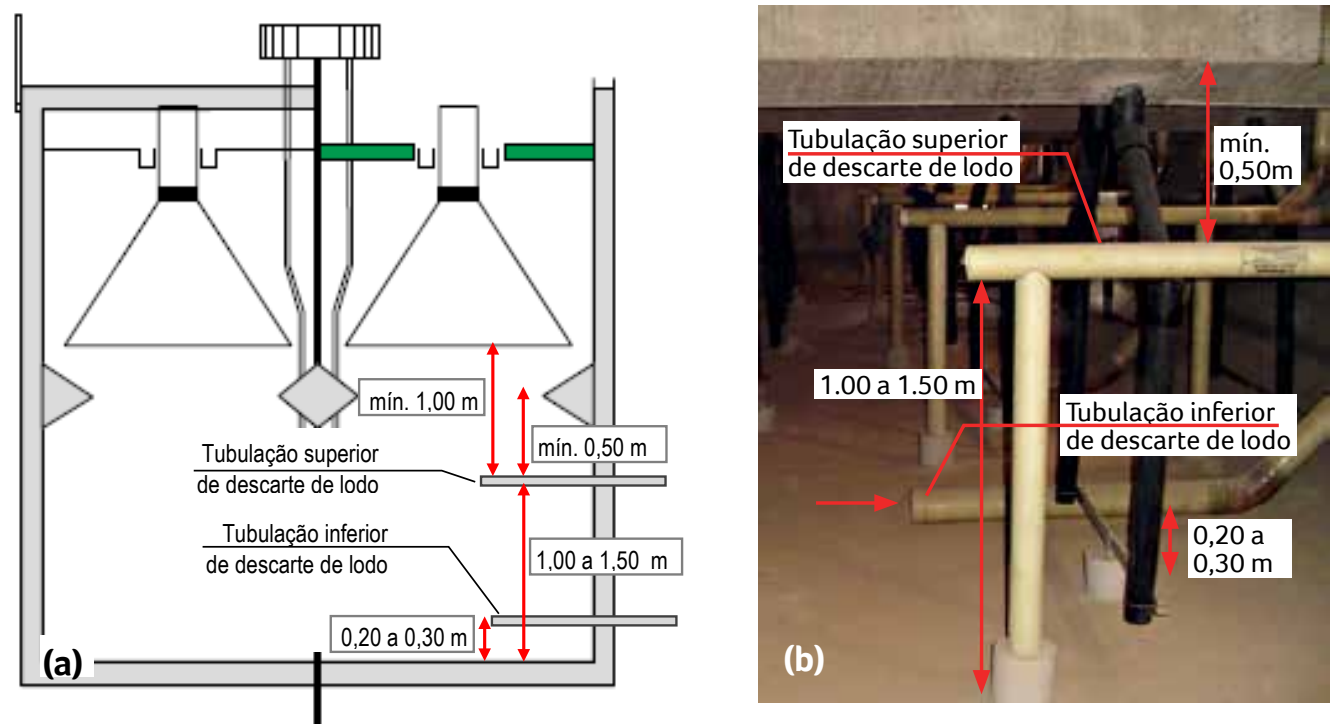

Figura 7 - Sistema de descarte de lodo do reator UASB: a) representação esquemática do posicionamento das tubulações inferiores e superiores de descarte de lodo; b) vista interna das tubulações inferiores e superiores de descarte de lodo.

\subsection{Definição das massas de lodo a serem mantidas e a serem descartadas do reator}

A fim de se evitar a perda indesejada de sólidos junto ao efluente final, deve-se manter a massa de lodo no interior do reator entre um valor mínimo, correspondente à biomassa suficiente para digerir a carga orgânica afluente, e um valor máximo, dependente da capacidade de retenção de lodo no reator UASB. O cálculo da massa mínima é reali- zado a partir da carga orgânica aplicada ao reator e da atividade metanogênica específica (AME) do lodo anaeróbio, conforme exemplificado a seguir. A AME pode ser definida como a capacidade máxima de produção de metano por um consórcio de microrganismos anaeróbios, realizada em condições controladas de laboratório, para viabilizar a atividade bioquímica máxima de conversão de substratos orgânicos a metano (CHERNICHARO, 2007).

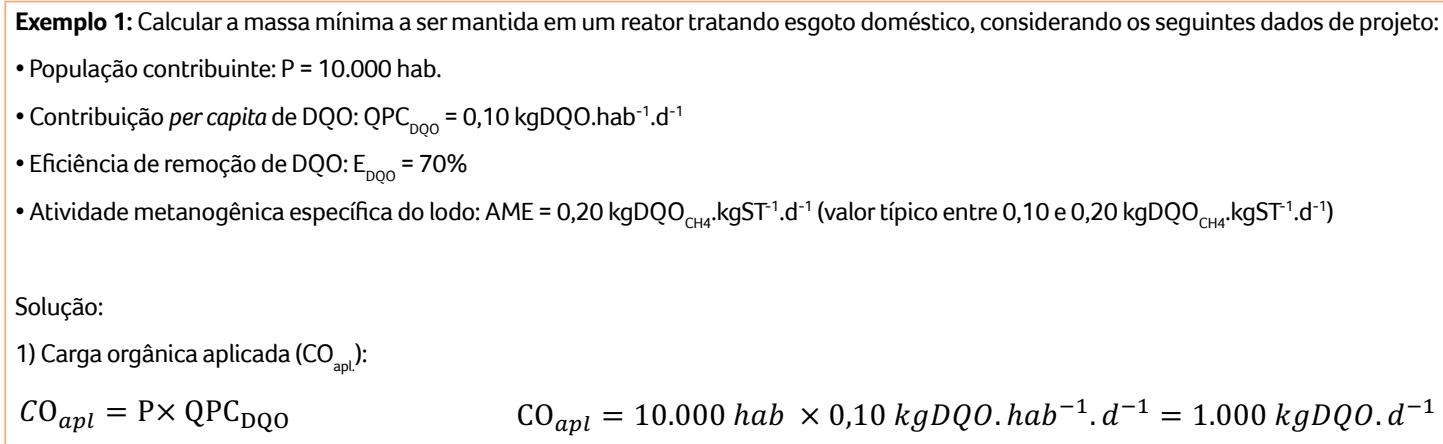

2) Carga orgânica removida $\left(\mathrm{CO}_{\text {remov. }}\right)$ :

$C O_{\text {remov }}=\mathrm{CO}_{\text {apl }} \times \mathrm{E}_{\mathrm{DQO}} \quad C O_{\text {remov }}=1.000 \mathrm{kgDQO} \cdot \mathrm{d}^{-1} \times 70 \%=700 \mathrm{kgDQO} \cdot \mathrm{d}^{-1}$

3) Massa mínima $\left(M_{\min }\right)$ :

$\mathrm{M}_{\min }=\frac{C O_{\text {remov }}}{\mathrm{AME}} \quad \mathrm{M}_{\min }=\frac{700 \mathrm{kgDQO} \cdot \mathrm{d}^{-1}}{0,20 \mathrm{kgDQO}_{\mathrm{CH} 4} \cdot \mathrm{kgSTV}^{-1} \cdot \mathrm{d}^{-1}}=3.500 \mathrm{kgSTV}$ 
Já para se definir a massa máxima de lodo que o reator consegue armazenar, sem que ocorra passagem de lodo para o compartimento de decantação e perda excessiva de sólidos no efluente, devem ser observados os resultados de monitoramento de sólidos suspensos e sólidos sedimentáveis no efluente do reator, bem como de concentrações de sólidos totais (ST) ao longo de toda a altura do compartimento de digestão (perfil de lodo), buscando-se inferir a partir de qual massa de lodo no interior do reator inicia-se maior perda de sólidos e deterioração da qualidade do efluente. Outra possibilidade, quando não se possui uma série histórica de dados que permita a definição da massa máxima, refere-se à manutenção da concentração de ST do lodo amostrado no ponto mais elevado do compartimento de digestão, localizado imediatamente antes do defletor de gases, sempre abaixo de 0,5\%.

\subsection{Definição da estratégia de descarte}

A partir da estimativa da produção de lodo no reator e da massa de lodo a ser descartada, calcula-se o volume de lodo a descartar de acordo com a estratégia de descarte adotada. Uma estratégia que vem sendo recomendada é a de se descartar pelo menos $50 \%$ da massa de lodo excedente a partir da tubulação superior ( 1,00 a 1,50 m acima do fundo). Para compensar os maiores volumes de descarte resultantes dessa prática, deve-se prever, nos novos projetos, um poço de adensamento $e$ homogeneização de lodo antes da unidade de desaguamento. $\mathrm{O}$ adensamento parcial do lodo possibilita que o sobrenadante seja retornado para o reator UASB, e que a fração mais concentrada seja adequadamente homogeneizada para se atingir a faixa ideal de teor de ST exigida pelo equipamento de desaguamento mecanizado. 0 descarte de lodo superior favorece ainda a manutenção de baixíssimas concentrações de ST na interface dos compartimentos de digestão e decantação, a qual deve permanecer sempre abaixo de $0,5 \% \mathrm{ST}$, conforme comentado anteriormente.

É recomendável a retirada pré-programada e continuada do lodo excedente para que o reator opere ciclicamente da forma mais estável possível. Os exemplos seguintes ilustram os cálculos das capacidades necessárias de sistemas de desaguamento natural e mecanizado para processamento do lodo descartado, em função da produção de lodo no reator anaeróbio e da estratégia de descarte adotada.

\footnotetext{
Exemplo 2: Dimensionar o sistema de desaguamento natural de lodo de reatores UASB, considerando os seguintes dados de projeto:

- População contribuinte: $P=10.000$ hab.

- Carga orgânica aplicada: $\mathrm{CO}_{\text {apl }}=1.000 \mathrm{kgDQ} O . \mathrm{d}^{-1}$

- Coeficiente de produção de lodo no reator $\operatorname{UASB}\left(0,10\right.$ a $\left.0,20 \mathrm{kgST} \cdot \mathrm{kgDQO}^{-1}\right): \mathrm{Y}_{\text {lodo }}=0,20 \mathrm{kgST} \cdot \mathrm{kgDQO}^{-1}$

- Massa específica do lodo (usualmente da ordem 1.020 a $1.040 \mathrm{kgST} . \mathrm{m}^{-3}$ ): $\mathrm{Y}=1.020 \mathrm{kgST} . \mathrm{m}^{-3}$

Observação: Os exemplos 2 e 3 contemplam apenas o coeficiente de produção de lodo no reator UASB. Caso a ETE receba outros tipos de contribuições (p. ex.: lodo aeróbio produzido na unidade de pós-tratamento, lodo de tanque séptico, lixiviado de aterro sanitário, efluentes não domésticos etc.) e/ou seja adotado o envio de lodo aeróbio da unidade de pós-tratamento (p. ex.: FBP, lodos ativados), para adensamento e estabilização nos reatores UASB, deve ser computado no cálculo do sistema de desaguamento o aumento no valor do coeficiente de produção de lodo devido a essas contribuições.

Solução:

1) Produção diária de lodo no reator $\left(\mathrm{P}_{\text {lodo }}\right)$

$\mathrm{P}_{\text {lodo }}=Y_{\text {lodo }} \times \mathrm{CO}_{\text {apl }} \quad \mathrm{P}_{\text {lodo }}=0,20 \mathrm{kgST}_{\mathrm{kgDQO}} \mathrm{kg}^{-1} \times 1.000 \mathrm{kgDQO} \cdot \mathrm{d}^{-1}=200 \mathrm{kgST}^{-\mathrm{d}^{-1}}$
} 


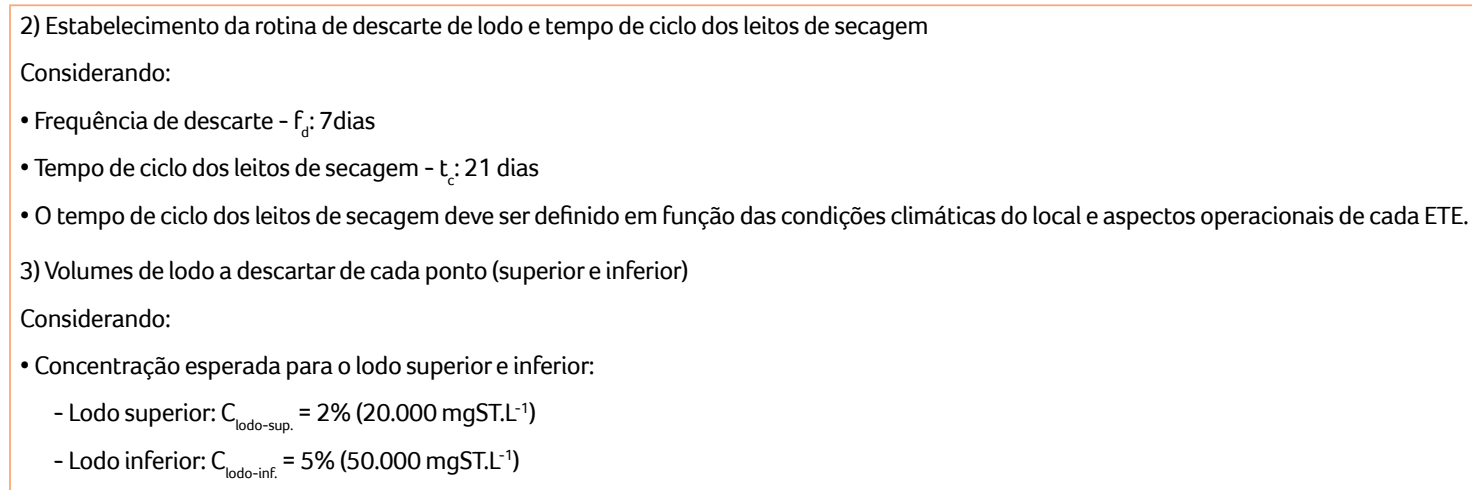

- Percentuais de descarte de lodo superior e inferior:

- Lodo superior: $50 \%$ em massa

- Lodo inferior: $50 \%$ em massa

$\mathrm{V}_{\text {lodo }}=\frac{\mathrm{P}_{\text {lodo }} \times \mathrm{f}_{\mathrm{d}}}{\gamma \times \mathrm{C}_{\text {lodo }}}$

$$
\begin{aligned}
& \mathrm{V}_{\text {lodo-sup. }}=\frac{200 \mathrm{kgST} \cdot \mathrm{d}^{-1} \times 7 \mathrm{~d} \times 50 \%}{1.020 \mathrm{kgST} \cdot \mathrm{m}^{-3} \times 2 \%}=34 \mathrm{~m}^{3} \\
& \mathrm{~V}_{\text {lodo-inf. }}=\frac{200 \mathrm{kgST} \cdot \mathrm{d}^{-1} \times 7 \mathrm{~d} \times 50 \%}{1.020 \mathrm{kgST} \cdot \mathrm{m}^{-3} \times 5 \%}=14 \mathrm{~m}^{3}
\end{aligned}
$$

4) Massa de lodo excedente descartada dos reatores $\left(M_{\text {lodo }}\right)$

$\mathrm{M}_{\text {lodo }}=\mathrm{P}_{\text {lodo }} \times \mathrm{f}_{\mathrm{d}} \quad \mathrm{M}_{\text {lodo }}=200 \mathrm{kgST} . \mathrm{d}^{-1} \times 7 \mathrm{~d}=1.400 \mathrm{kgST}$

5) Volume de lodo excedente descartada dos reatores $\left(\mathrm{V}_{\text {lodo }}\right)$

$\mathrm{V}_{\text {lodo }}=\mathrm{V}_{\text {lodo-sup. }}+\mathrm{V}_{\text {lodo-inf. }} \quad \mathrm{V}_{\text {lodo }}=34 \mathrm{~m}^{3}+14 \mathrm{~m}^{3}=48 \mathrm{~m}^{3}$

6) Dimensionamento dos leitos de secagem

- Altura da lâmina de lodo no leito de secagem $\left(\mathrm{H}_{\text {leito }}\right)$

- Adotou-se $\mathrm{H}_{\text {leito }}=0,35 \mathrm{~m}$.

- A altura da lâmina de lodo no leito de secagem não deve exceder a 0,40 m.

- Área necessária para cada leito de secagem $\left(\mathrm{A}_{\text {leito }}\right)$

$\mathrm{A}_{\text {leito }}=\frac{\mathrm{V}_{\text {lodo }}}{\mathrm{H}_{\text {leito }}} \quad \mathrm{A}_{\text {leito }}=\frac{48 \mathrm{~m}^{3}}{0,35 \mathrm{~m}}=137 \mathrm{~m}^{2}$

- Número de unidades e geometria dos leitos de secagem

- Considerando a realização de descartes semanais e tempo de ciclo dos leitos de secagem de 21 dias, adotaram-se 4 células de 10,0 m x 14,0 m.

- Taxa de aplicação de sólidos resultante em cada leito de secagem $\left(\mathrm{T}_{\mathrm{x}-\mathrm{ST}}\right)$

$\mathrm{T}_{\times-\mathrm{ST}}=\frac{\mathrm{M}_{\text {lodo }}}{\mathrm{A}_{\text {leito }}} \quad \mathrm{T}_{\mathrm{x}-\mathrm{ST}}=\frac{1.400 \mathrm{kgST}}{140 \mathrm{~m}^{2}}=10 \mathrm{kgST} . \mathrm{m}^{-2}$

- De acordo com a NBR 12.209, a descarga de lodo nos leitos de secagem não pode exceder a carga de sólidos em suspensão totais de 15 kgST.m² de área de secagem, em cada ciclo de operação (ABNT, 2011). 
Na Figura 8 é apresentado um desenho esquemático mostrando a rotina de descarte de lodo e de limpeza dos leitos de secagem (LS).

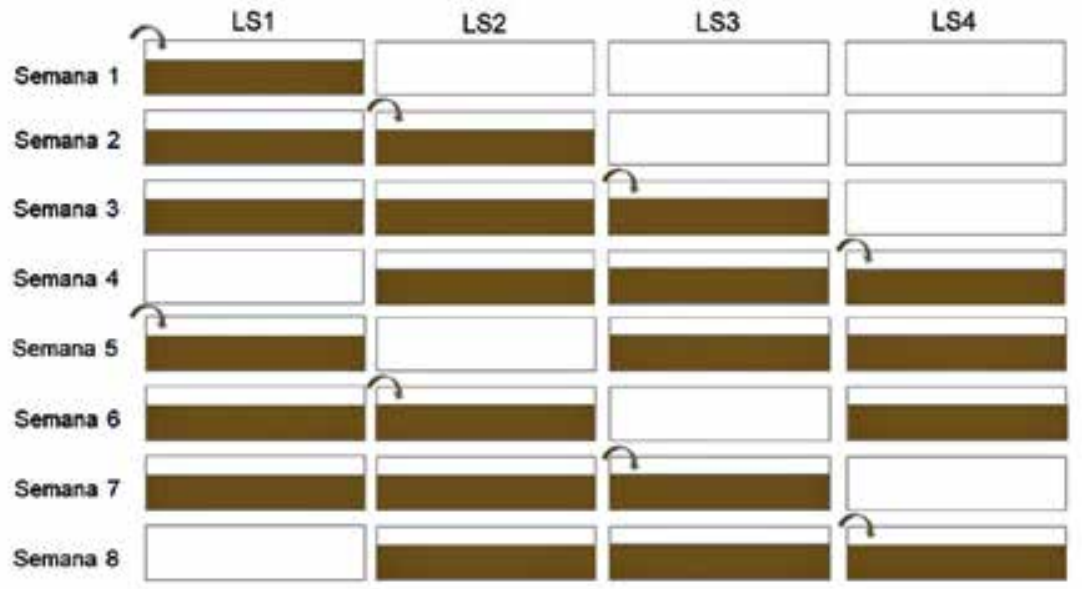

Figura 8 - Ilustração esquemática da rotina de descarte de lodo e limpeza dos leitos de secagem do Exemplo 2.

Exemplo 3: Dimensionar o sistema de desaguamento mecanizado de lodo de reatores UASB, considerando os seguintes dados de projeto:

- População contribuinte: $P=100.000$ hab.

- Carga orgânica aplicada: $\mathrm{CO}_{\text {apl }}=10.000 \mathrm{kgDQO} \cdot \mathrm{d}^{-1}$

- Coeficiente de produção de lodo no reator UASB $\left(0,10\right.$ a 0,20 kgST.kgDQO-1): $\mathrm{Y}_{\text {lodo }}=0,20 \mathrm{kgST} \cdot \mathrm{kgDQO}^{-1}$

- Massa específica do lodo (usualmente da ordem 1.020 a $1.040 \mathrm{kgST} . \mathrm{m}^{-3}$ ): $\mathrm{\gamma}=1.020 \mathrm{kgST} . \mathrm{m}^{-3}$

Solução:

1) Cálculo da produção diária de lodo $\left(P_{\text {lodo }}\right)$

$\mathrm{P}_{\text {lodo }}=Y_{\text {lodo }} \times \mathrm{CO}_{\text {apl }}$

$$
\mathrm{P}_{\text {lodo }}=0,20 \mathrm{kgST} \cdot \mathrm{kgDQO} \mathrm{O}^{-1} \times 10.000 \mathrm{kgDQO} \cdot \mathrm{d}^{-1}=2.000 \mathrm{kgST} \cdot \mathrm{d}^{-1}
$$

2) Cálculo dos volumes diários de lodo a descartar de cada ponto (superior e inferior)

- Concentração esperada para o lodo superior e inferior:

- Lodo superior: $\mathrm{C}_{\text {lodo-sup. }}=2 \%\left(20.000 \mathrm{mgST}^{-L^{-1}}\right)$

- Lodo inferior: $\mathrm{C}_{\text {lodo-inf. }}=5 \%\left(50.000 \mathrm{mgST} . \mathrm{L}^{-1}\right)$

- Percentuais de descarte de lodo superior e inferior:

- Lodo superior: $50 \%$ em massa

- Lodo inferior: $50 \%$ em massa

$\mathrm{V}_{\text {lodo }}=\frac{\mathrm{P}_{\text {lodo }}}{\gamma \times \mathrm{C}_{\text {lodo }}}$

$$
\begin{aligned}
& \mathrm{V}_{\text {lodo-sup. }}=\frac{2.000 \mathrm{kgST} \cdot \mathrm{d}^{-1} \times 50 \%}{1.020 \mathrm{kgST} \cdot \mathrm{m}^{-3} \times 2 \%}=49,0 \mathrm{~m}^{3} \cdot \mathrm{d}^{-1} \\
& \mathrm{~V}_{\text {lodo-inf. }}=\frac{2.000 \mathrm{kgST} \cdot \mathrm{d}^{-1} \times 50 \%}{1.020 \mathrm{kgST} \cdot \mathrm{m}^{-3} \times 5 \%}=19,6 \mathrm{~m}^{3} \cdot \mathrm{d}^{-1}
\end{aligned}
$$

3) Volume diário de lodo a ser descartado $\left(V_{\text {lodo }}\right)$

$\mathrm{V}_{\text {lodo }}=\mathrm{V}_{\text {lodo-sup. }}+\mathrm{V}_{\text {lodo-inf. }} \quad \mathrm{V}_{\text {lodo }}=49,0 \mathrm{~m}^{3} \cdot d^{-1}+19,6 \mathrm{~m}^{3} \cdot d^{-1}=68,6 m^{3} \cdot d^{-1}$ 
4) Concentração média do lodo enviado para o sistema de desaguamento mecanizado ( $\left.\mathrm{C}_{\text {lodo-média }}\right)$

$\mathrm{C}_{\text {lodo-média }}=\frac{\mathrm{C}_{\text {lodo-sup. }} \times \mathrm{V}_{\text {lodo-sup. }}+\mathrm{C}_{\text {lodo-inf. }} \times \mathrm{V}_{\text {lodo-inf }}}{V_{\text {lodo }}}$

$\mathrm{C}_{\text {lodo-média }}=\frac{2 \% \times 49,0 \mathrm{~m}^{3} \cdot \mathrm{d}^{-1}+5 \% \times 19,6 \mathrm{~m}^{3} \cdot \mathrm{d}^{-1}}{68,6 \mathrm{~m}^{3} \cdot \mathrm{d}^{-1}}=2,8 \%$

5) Carga de sólidos a ser processada diariamente pelo sistema de desaguamento mecanizado

$C S=\mathrm{V}_{\text {lodo }} \times \gamma \times \mathrm{C}_{\text {lodo-média }} \quad C S=68,6 \mathrm{~m}^{3} \cdot \mathrm{d}^{-1} \times 1.020 \mathrm{kgST} . \mathrm{m}^{-3} \times 2,8 \%=1.959,2 \mathrm{kgST} . \mathrm{d}^{-1}$

6) Dimensionamento do sistema de desaguamento mecanizado de lodo com a utilização de centrifuga

- Definição do número de centrífugas

- Considerou-se: 1 unidade em operação + 1 rodízio e reserva.

- Ressalta-se que o número de unidades em operação e reserva é função do porte da estação e da quantidade de lodo gerado, bem como da estrutura de manutenção a ser implantada e da disponibilidade de rotas alternativas de disposição do lodo.

- Definição da rotina operacional

- Considerou-se: 5 dias por semana e 8 horas diárias de funcionamento.

- Cálculo da capacidade da centrífuga necessária para o processamento do lodo excedente (Cc):

$$
\begin{array}{ll}
C_{c-\text { volume }}=\frac{V_{\text {lodo }} \times 7 d}{5 d} & C_{c \text {-volume }}=\frac{68,6 \mathrm{~m}^{3} \cdot \mathrm{d}^{-1} \times 7 \mathrm{~d}}{5 \mathrm{~d}}=96,0 \mathrm{~m}^{3} \cdot \mathrm{d}^{-1} \\
C_{c-\text { massa }}=\frac{C S \times 7 d}{5 d} & C_{c-\text { mass }}=\frac{1.959,2 \mathrm{kgST} \cdot \mathrm{d}^{-1} \times 7 \mathrm{~d}}{5 \mathrm{~d}}=2.742,9 \mathrm{kgST} \cdot \mathrm{d}^{-1}
\end{array}
$$

- O sistema de desaguamento deve ser capaz de processar diariamente $96,0 \mathrm{~m}^{3} . \mathrm{d}^{-1}$ ou $2.742,9 \mathrm{kgST}^{\mathrm{d}} \mathrm{d}^{-1}$, a fim de compensar o não processamento de lodo aos finais de semana.

- Considerando 8 horas diárias de funcionamento, a centrífuga deve ter capacidade para processar $12 \mathrm{~m}^{3} \cdot \mathrm{h}^{-1}$ ou $342,9 \mathrm{kgST} \cdot \mathrm{h}^{-1}$.

- Importante ressaltar que o volume (e a massa) total de lodo a ser processado diariamente deverá ser dividido pelo número de reatores que integram a ETE, de modo a manter a massa de lodo em cada reator sempre acima da mínima recomendada (ver Exemplo 1). Ademais, o volume a ser descartado de cada reator deve ser dividido pelo número de válvulas superiores e inferiores, sendo efetuado primeiro o descarte da linha de lodo superior e depois da linha de lodo inferior.

- Para facilitar e agilizar a operação de descarte do lodo, uma alternativa é a realização do descarte do lodo de apenas alguns reatores por dia, em esquema de rodízio entre todos os reatores da ETE, desde que a massa de lodo em cada reator seja mantida sempre acima da mínima recomendada.

- Seleção do equipamento

- Para a seleção do equipamento disponível comercialmente, as seguintes informações devem ser enviadas para os fornecedores: (i) vazão de esgoto afluente à ETE; (ii) volume e carga de sólidos a serem processados por dia; (ii) concentrações de sólidos do lodo a ser processado; e (iv) dados sobre a rotina operacional (número de horas de funcionamento por semana). 


\subsection{Definição das características dos sistemas de desaguamento}

Para o dimensionamento do sistema de desaguamento de lodo, seja ele natural ou mecanizado, além da estimativa da produção de lodo levando em conta todas as possíveis contribuições que possam impactar o coeficiente de produção de lodo $\left(\mathrm{Y}_{\text {lodo }}\right)$, é de fundamental importância considerar as especificidades de cada local, as condições climáticas, as condições operacionais, bem como questões logísticas e administrativas. Ademais, é essencial considerar a possibilidade do descarte de lodo a duas alturas, conforme exemplificado anteriormente, o que culmina em um maior volume de lodo de descarte. Ressalta-se que essa desvantagem pode ser minimizada com a previsão de poço para adensamento e homogeneização do lodo, como comentado anteriormente.

\subsubsection{Desaguamento natural}

Em ETEs com desaguamento natural em leitos de secagem, os descartes devem ser realizados em bateladas, sendo a frequência compatível com a capacidade de retenção e armazenamento de lodo nos reatores, o tempo médio de secagem (de acordo com as condições climáticas do local) e o contrato com o prestador de serviço referente à remoção e transporte do lodo desaguado.

Em relação ao dimensionamento dos leitos de secagem, deve-se atentar para a necessidade de modulação (em quantidade e dimensões), a qual deve estar muito bem associada ao planejamento (frequência e volume) de descarte de lodo e de limpeza dos leitos de secagem, de modo a se evitar a realização de descarte sobre descarte, ou seja, carga de lodo sobre carga de lodo, o que pode acelerar a colmatação dessas unidades.

\subsubsection{Desaguamento mecanizado}

Já em ETEs onde se utilizam processos de desaguamento mecanizado, o descarte de lodo deve ser realizado diariamente e a magnitude dos descartes deve corresponder à produção diária de lodo considerando todos os reatores. Entretanto, essa rotina operacional deve ser adotada apenas quando a massa de lodo nos reatores estiver abaixo do valor máximo adotado ou a concentração de ST no ponto de amostragem superior for inferior a 0,5\%. Em situações de excesso de lodo nos reatores UASB, as operações de descarte e de funcionamento do sistema de desaguamento mecanizado devem ser intensificadas.

A definição da rotina operacional de descarte de lodo deve ser compatível com os seguintes aspectos principais: i) a escala dos operadores; ii) os contratos de prestadores de serviços referentes ao transporte do lodo desaguado e à realização de manutenções preventivas e corretivas; iii) a possibilidade de paralisações; iv) a disponibilidade de produtos químicos e peças de reposição. Adicionalmente, deve-se avaliar a possibilidade de redundância dos equipamentos críticos e/ou a previsão de leitos de secagem (em casos específicos até mesmo a redundância), como alternativa em caso de paralisações e/ou manutenções dos equipamentos do sistema de desaguamento, evitando assim situações de passivo de lodo no interior dos reatores, o que pode acarretar na perda de sólidos junto ao efluente.

\section{ORIGEM E PROBLEMAS RELACIONADOS À ACUMULAÇÃO DE ESCUMA}

Em reatores UASB, a formação de escuma pode ocorrer em dois locais distintos: i) na superfície do compartimento de decantação; ii) no interior do separador trifásico (STF), na interface de liberação dos gases formados durante a digestão anaeróbia (Figura 9). 


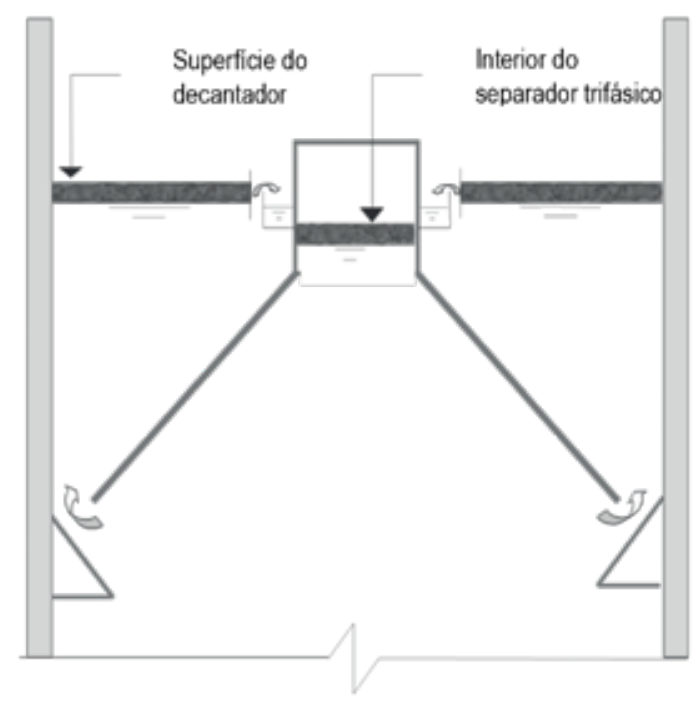

Figura 9 - Identificação dos pontos de acumulação de escuma em reatores UASB.

Fonte: Chernicharo (2007)

\subsection{Escuma acumulada na superfície do compartimento de decantação}

A escuma acumulada na superfície dos compartimentos de decantação dos reatores UASB, embora se caracterize como um resíduo muito concentrado, apresenta coeficientes de acumulação relativamente baixos, sendo possível projetar os compartimentos de decantação sem retentores de escuma, a fim de possibilitar que esse material seja descarregado junto com o efluente, sem acarretar na deterioração significativa da sua qualidade. Entretanto, é essencial garantir o adequado nivelamento $e$ fixação das calhas coletoras de efluente e a vedação na instalação dos vertedores, de forma a evitar fluxos preferenciais e o acúmulo de escuma na parte superior dos compartimentos de decantação, conforme mostrado nas Figuras 10a e 10b.

É importante salientar que a taxa de acumulação de escuma nos compartimentos de decantação depende também do adequado gerenciamento do lodo excedente. A ausência ou o descarte do lodo excedente com uma frequência não compatível com a produção de lodo no sistema pode acarretar em uma maior perda de sólidos para o compartimento de decantação. Uma vez no decantador, esse lodo se agrega à camada de escuma e passa a conferir o aspecto de "lodo flotado" juntamente com a escuma (Figura 10c). Essa situação tende a se agravar quando o reator opera com sobrecarga hidráulica e velocidades ascensionais mais elevadas que as previstas em projeto. Se não gerenciado adequadamente, o acúmulo excessivo de escuma no compartimento de decantação pode contribuir para a deterioração da qualidade do efluente final.
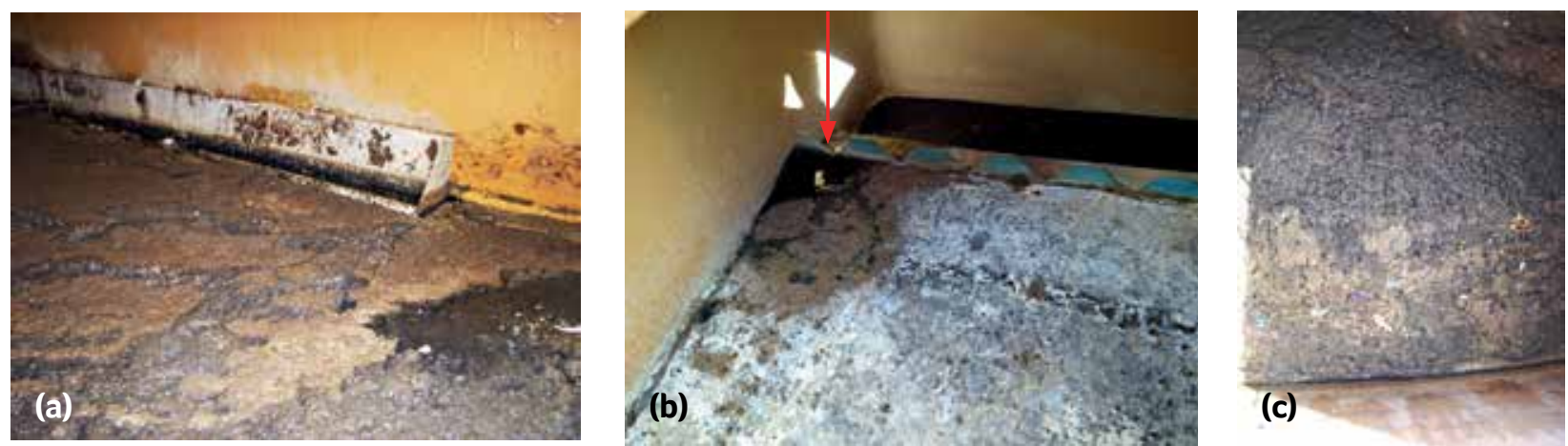

Figura 10 - Acúmulo de escuma no compartimento de decantação devido à: (a) calhas coletoras de efluentes desniveladas; (b) falta de vedação na instalação dos vertedores (o efluente passa entre a placa vertedora em fibra de vidro e a calha coletora em concreto); (c) falta de descarte de lodo e sobrecarga hidráulica no reator. 


\subsection{Escuma acumulada no interior do separador trifásico}

A ausência ou ineficiência dos dispositivos de remoção da escuma acumulada no interior do separador trifásico, associada a condições precárias de acesso, falta de condições de segurança ocupacional e não existência de protocolo sistematizado para a remoção desse material, pode levar ao espessamento e solidificação da camada de escuma (Figura 11a).

Essa camada de escuma pode impedir a passagem natural do biogás gerado no reator, podendo ocasionar sua passagem para o compartimento de decantação, comprometendo a retenção de sólidos e levando à deterioração da qualidade do efluente (LETTINGA e HULSHOFF, 1991; SOUZA et al., 2006). Em alguns casos, o impedimento da passagem natural do biogás acarreta no seu acúmulo e no aumento da pressão sob a camada espessa de escuma, resultando na geração de esforços estruturais elevados nas paredes do separador trifásico. A depender da magnitude desses esforços e da qualidade estrutural das paredes do separador trifásico, podem ocorrer danos de desnivelamento, de torção e até mesmo de ruptura desta estrutura (Figuras 11b e 11c). Ademais, o rompimento abrupto da camada de escuma pelo biogás sob pressão excessiva pode provocar a movimentação de placas solidificadas de escuma e a torção das paredes do separador trifásico (RAMOS, 2008; MIKI, 2010; van LIER et al., 2011). A propensão à ruptura do separador trifásico encontra-se fortemente associada ao tipo de material empregado nessas estruturas, notadamente, quando são confeccionados com materiais de menor resistência, a exemplo de lonas plásticas, chapas e telhas de amianto, e até mesmo de fibra de vidro de qualidade inferior.
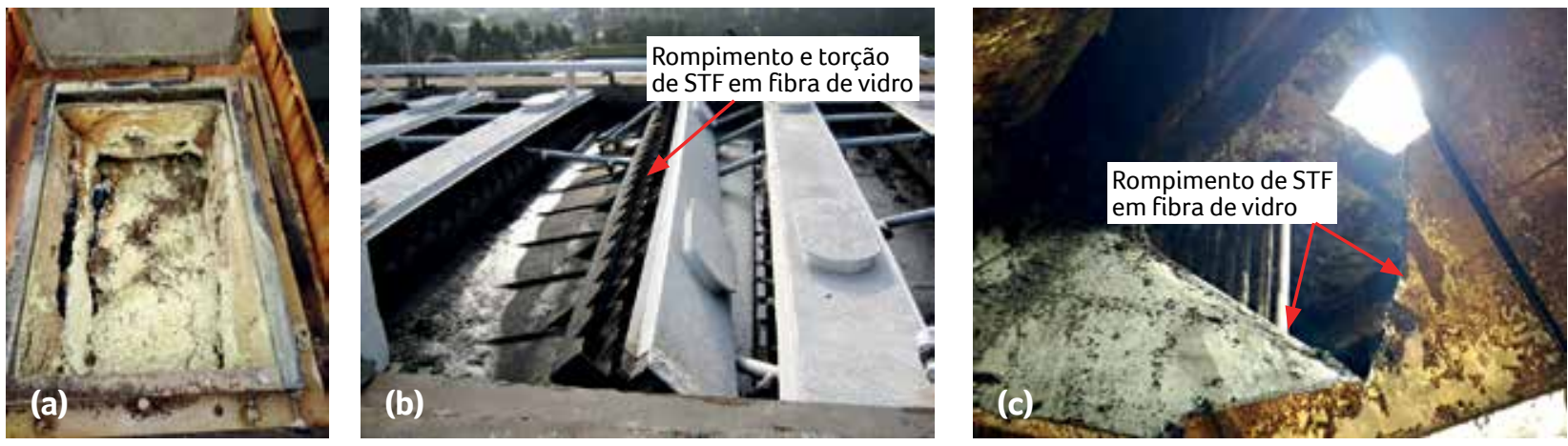

Figura 11 - (a) Escuma solidificada no interior do separador trifásico; (b e c) Rompimento de separador trifásico.

A passagem do biogás para o compartimento de decantação também tem impacto direto no aumento dos níveis de emissão de gases odorantes e de efeito estufa. Adicionalmente, acarreta a redução da recuperação de biogás para fins de queima e/ou de aproveitamento energético.

Valem aqui as mesmas considerações feitas anteriormente acerca do "lodo flotado" que se agrega à camada de escuma do compartimento de decantação, em decorrência do excesso de lodo no compartimento de digestão e de sobrecargas hidráulicas no reator.

Ademais, são válidas também as preocupações acerca dos detritos (lixo) não retidos no tratamento preliminar e que adentram ao reator. Uma parcela significativa dos detritos mais leves irá flotar e se agregar à camada de escuma no interior do separador trifásico ou na superfície do compartimento de decantação. 


\section{POSSIVEIS APRIMORAMENTOS RELACIONADOS AO GERENCIAMENTO DA ESCUMA}

A adoção das medidas descritas a seguir pode contribuir significativamente para o melhor gerenciamento da escuma. Ressalta-se que as medidas de sensibilização do usuário e melhoria do tratamento preliminar também são fundamentais para esse gerenciamento, uma vez que grande parte dos detritos pode vir a constituir a camada de escuma. Ademais, as medidas descritas para o gerenciamento do lodo impactam a formação e acumulação de escuma nos reatores UASB, logo devem ser tomadas em conjunto com as medidas descritas a seguir.

\subsection{Controle sobre o recebimento de efluentes não domésticos}

Alguns tipos de efluentes não domésticos, tais como lodo de tanques sépticos e de efluentes industriais com elevado teor de óleos e graxas (p. ex.: laticínios, abatedouros, frigoríficos), podem contribuir para o incremento da formação e acumulação de escuma nos reatores UASB e, consequentemente, agravar os problemas mencionados anteriormente. Recomenda-se, portanto, rigoroso controle no recebimento destas e de outras contribuições que possam colaborar para o agravamento da formação de escuma nos reatores UASB.

\subsection{Melhor controle sobre a formação de escuma no compartimento de decantação}

Para se alcançar um melhor controle sobre a formação de escuma na superfície do compartimento de decantação, devem ser consideradas as diretrizes apresentadas no Quadro 3.

Quadro 3 - Principais diretrizes para projeto, construção e operação relacionadas ao controle da formação de escuma no compartimento de decantação.

\footnotetext{
- Melhoria do projeto, da confecção e da instalação das calhas coletoras de efluente (garantia de lâmina vertedora mínima de 15 mm e fixação adequada que garanta nivelamento e resistência à torção).

- Correto dimensionamento da estrutura de extravasão de esgoto e/ou da estação elevatória de alimentação dos reatores, de modo a se evitar sobrecargas hidráulicas e velocidades excessivas nos compartimentos de digestão e de decantação do reator.

• Correto gerenciamento do lodo, de modo a evitar passagem excessiva e "flotação" de lodo no compartimento de decantação.
}

\subsection{Utilização de separadores trifásicos equipados com dispositivo de remoção de escuma}

$\mathrm{Na}$ evolução das alternativas de aprimoramento de reatores UASB, os projetos mais recentes têm incorporado canaletas de coleta de escuma no interior do separador trifásico (Figura 12), de forma a possibilitar a remoção hidrostática. Alguns projetos incorporam, adicionalmente, aspersores com jatos pressurizados de água com o intuito de auxiliar no carreamento da escuma para dentro das canaletas de coleta. Não se tem certeza da real necessidade desses aspersores, tendo em vista que a escuma removida com maior frequência ( 2 a 3 vezes por semana) é bastante fluída e não necessita de jatos de água para a sua remoção efetiva (ROSA et al., 2012; SANTOS, 2014; DÍAZ FLÓREZ, 2016). 

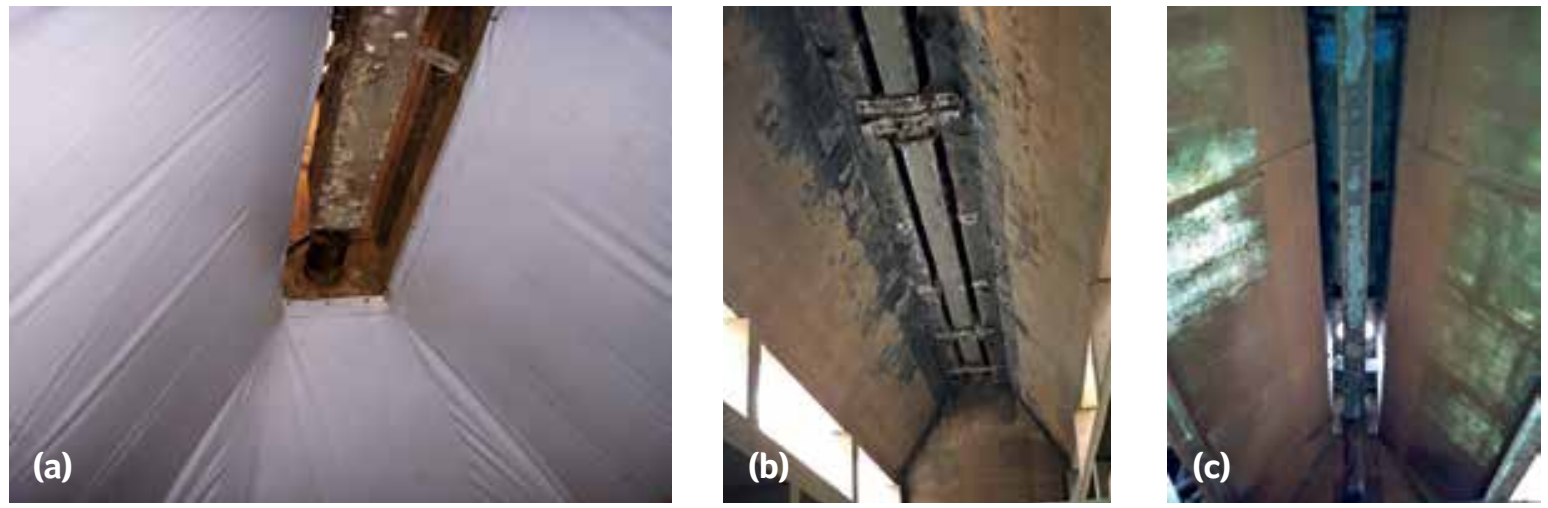

Figura 12 - Separadores trifásicos com canaleta interna de coleta de escuma: a) STF confeccionado em concreto e lona, com canaleta em alumínio; b) STF confeccionado em concreto, com canaleta em PRFV; e c) STF confeccionado em PRFV, com canaleta em PRFV.

Uma alternativa à utilização de separadores trifásicos contínuos (tronco-piramidais retangulares - ver Figura 16), equipados com canaletas longas, é a utilização de separadores trifásicos menores, tronco-piramidais quadrangulares, equipados com coletores de escuma na forma de bojo (cuba) em sua parte interna, conforme mostrado na Figura 13.
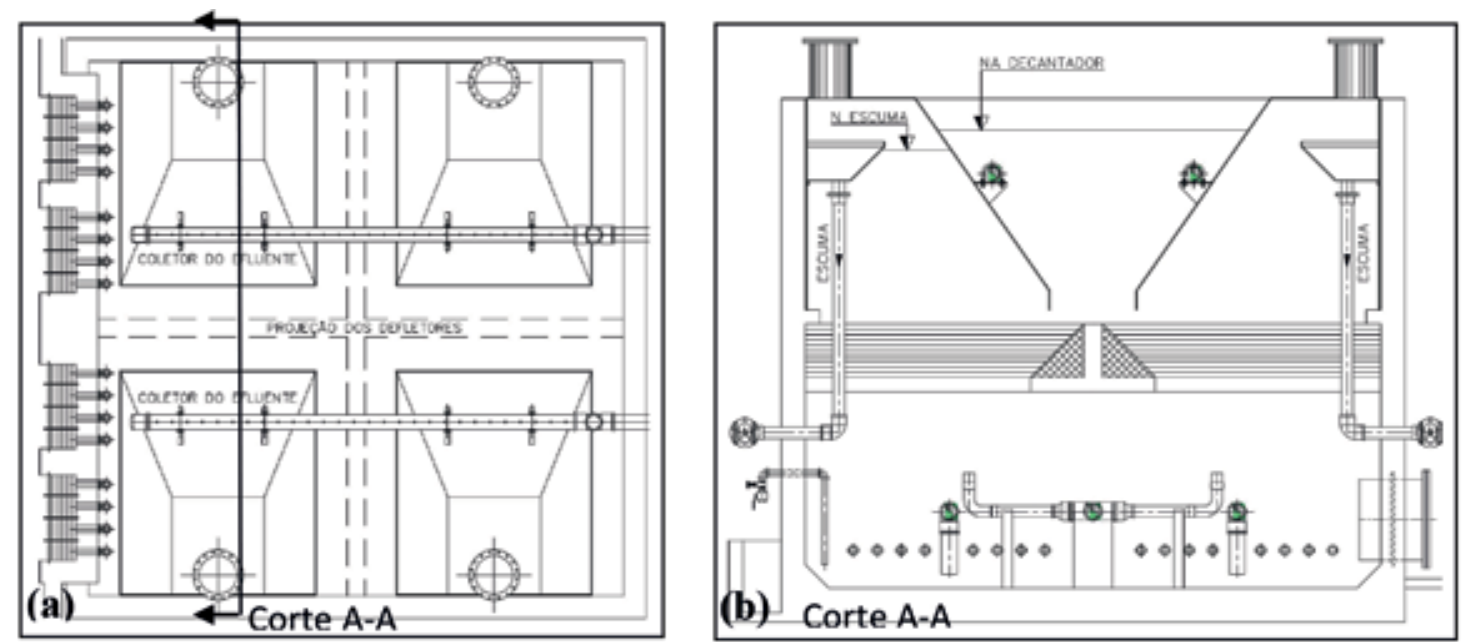

Figura 13 - Separador trifásico tronco-piramidal quadrangular equipado com coletor interno de escuma. a) vista em planta; b) corte transversal.

O procedimento de remoção hidrostática baseia-se na alteração do nível d'água no interior do separador trifásico, de modo a possibilitar que a escuma verta para a canaleta, interna ao separador, e seja encaminhada para a tubulação de descarte, externa ao reator. A alteração do nível d'água no interior do separador trifásico é alcançada pelo incremento ou redução da pressão na linha de gás compreendida entre o separador trifásico e o selo hídrico localizado no topo de cada reator UASB. Na Figura 14 está ilustrada a representação esquemática do sistema para remoção hidrostática da escuma. 


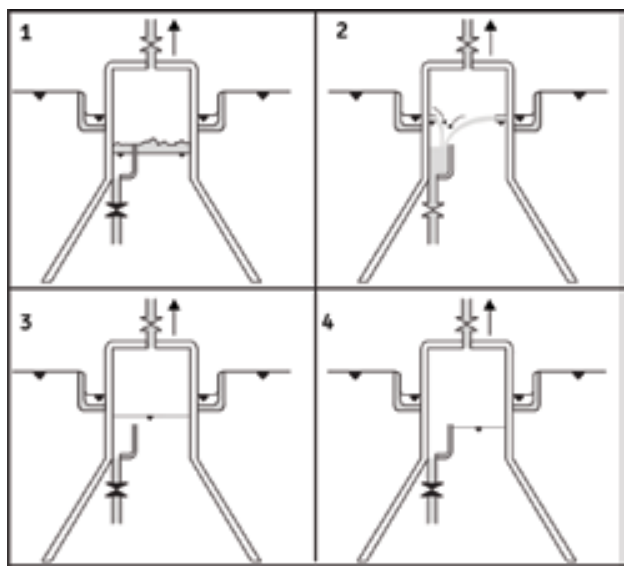

Sequência de procedimentos

1. Níveis de escuma durante a operação normal do reator (linha de gás pressurizada, de modo a manter o nível de escuma 2 a $3 \mathrm{~cm}$ abaixo da borda superior da canaleta interna).

2. Elevação do nível de escuma, conseguido com o alívio da pressão da linha de gás, de forma a possibilitar a entrada de escuma na canaleta interna.

3. Fechamento da válvula de esgotamento da canaleta interna.

4. Aumento da pressão da linha de gás, retornando à condição operacional mostrada em 1.

Figura 14 - Representação esquemática do sistema para remoção hidrostática da escuma.

Esse dispositivo para remoção hidrostática foi testado com bons resultados em reatores UASB em escalas de demonstração e plena, tendo sido observadas eficiências de remoção entre $75 \%$ e 90\% (ROSA et al., 2012; SANTOS, 2014; DÍAZ FLÓREZ, 2016).
Ressalta-se que tal dispositivo só funciona adequadamente para a remoção de escuma no seu estado fluido (não excessivamente adensada e solidificada). No Quadro 4 são apresentadas as principais diretrizes a serem consideradas no projeto, construção e operação do dispositivo de remoção de escuma.

Quadro 4 - Diretrizes para projeto, construção e operação do dispositivo de remoção de escuma.

\footnotetext{
- A quantidade de escuma acumulada no interior do separador trifásico deve ser verificada para cada condição específica, considerando a qualidade do esgoto bruto, a eficiência do tratamento preliminar e as características construtivas do reator, quando do início de operação do dispositivo de remoção de escuma.

- O separador trifásico deve ser integrado ao selo hídrico para permitir o controle das pressões internas e, consequentemente, o ajuste dos níveis d’água em relação à canaleta de coleta de escuma (Figuras 15a e 16).

- As canaletas de coleta de escuma devem ser preferencialmente posicionadas junto a uma das paredes do separador trifásico e não junto ao centro. 0 posicionamento da canaleta junto a uma das laterais possibilita maior lâmina vertente e maior eficiência na remoção de escuma. Na Figura $15 b$ é mostrada uma canaleta em seção triangular.

- Correto posicionamento da canaleta de coleta de escuma quando da construção, tendo em vista que a instalação em níveis diferentes dos especificados em projeto podem inviabilizar a adequada pressurização e o funcionamento do dispositivo.

- Prever pontos de inspeção e válvulas nas tubulações de saída de escuma de cada separador trifásico, visando à identificação de pontos de entupimento e a não ocorrência de perda de carga hidráulica desigual, observada quando da instalação de apenas uma válvula (Figura 15c).

- Prever bocais de extração ao longo do comprimento da canaleta de coleta de escuma, a fim de permitir condições hidráulicas mais adequadas para o escoamento da escuma (Figura 17).

- Com base nas experiências relacionadas ao desenvolvimento do separador trifásico modular Étsus-1000, para a configuração de múltiplos bocais de extração, uma largura de $15 \mathrm{~cm}$ para a canaleta de coleta de escuma é suficiente para garantir vazões adequadas de escoamento e, também, adequadas taxas de liberação de biogás (taxa de liberação mínima:

$1,0 \mathrm{~m}^{3}$ biogás. $\left.\mathrm{m}^{-2} \cdot \mathrm{h}^{-1}\right)$ na área exterior a canaleta de coleta de escuma.

- Garantir a estanqueidade do compartimento de gás, de modo a possibilitar o estabelecimento de pequenas pressões na linha de biogás (10 a 15 cm.c.a).

- A frequência ideal de remoção de escuma no interior dos separadores trifásicos deve ser estabelecida por meio de inspeção visual, que pode ser realizada a partir da abertura das escotilhas de fechamento hermético (ou a partir de visores transparentes, quando disponíveis), antes e depois de cada operação de descarte. A prática operacional do reator possibilitará estabelecer a melhor rotina de descarte (frequência e tempo de descarte, grau de abertura das válvulas, volumes removidos).

- Sempre que possível, prever válvulas motorizadas para facilitar a operação de remoção de escuma.
} 

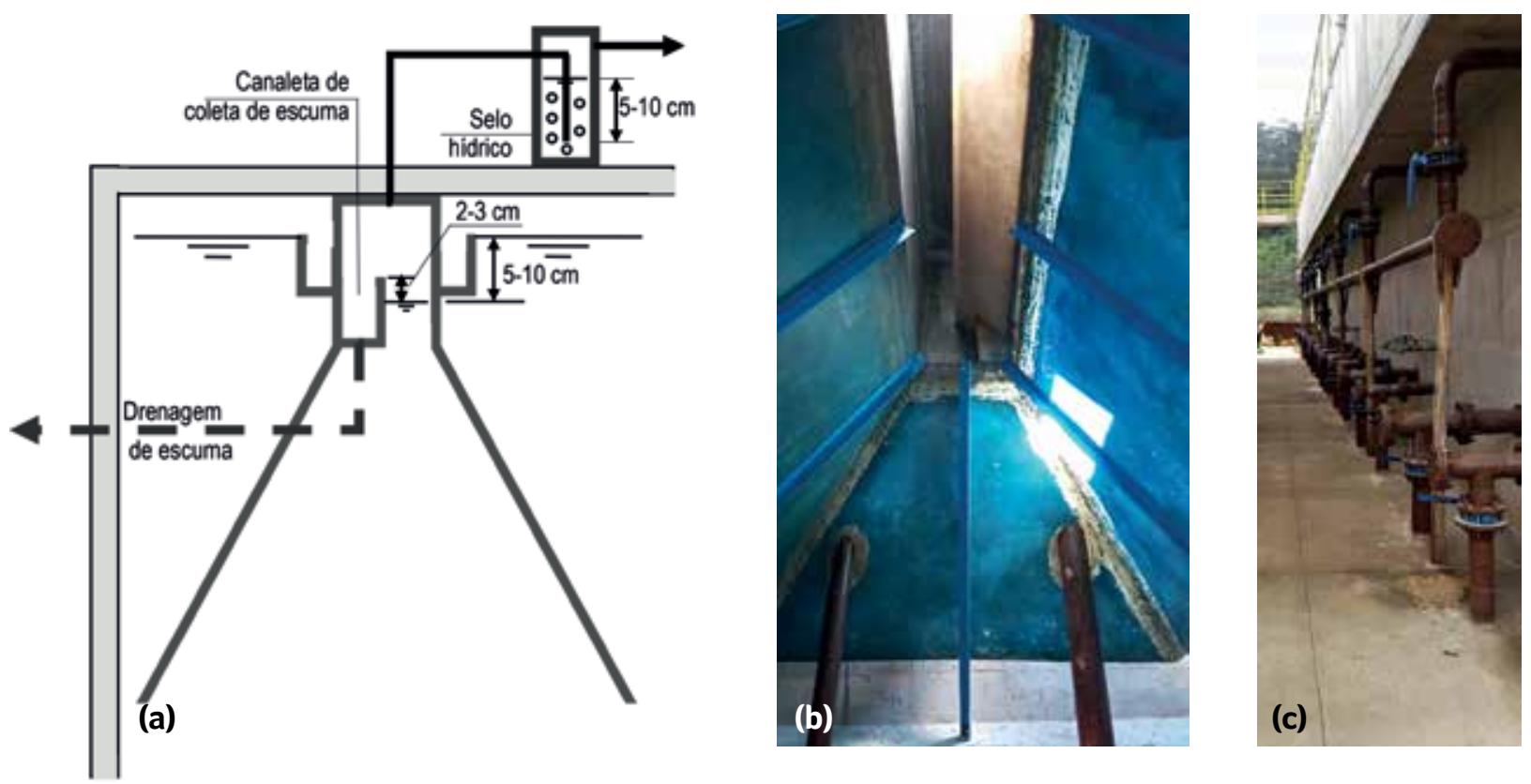

Figura 15 - Dispositivo de remoção hidrostática de escuma: (a) ilustração esquemática do controle de pressão e nível de escuma no interior do STF; (b) vista de canaleta de coleta de escuma em seção triangular; (c) válvulas nas tubulações de saída de escuma de cada separador trifásico.
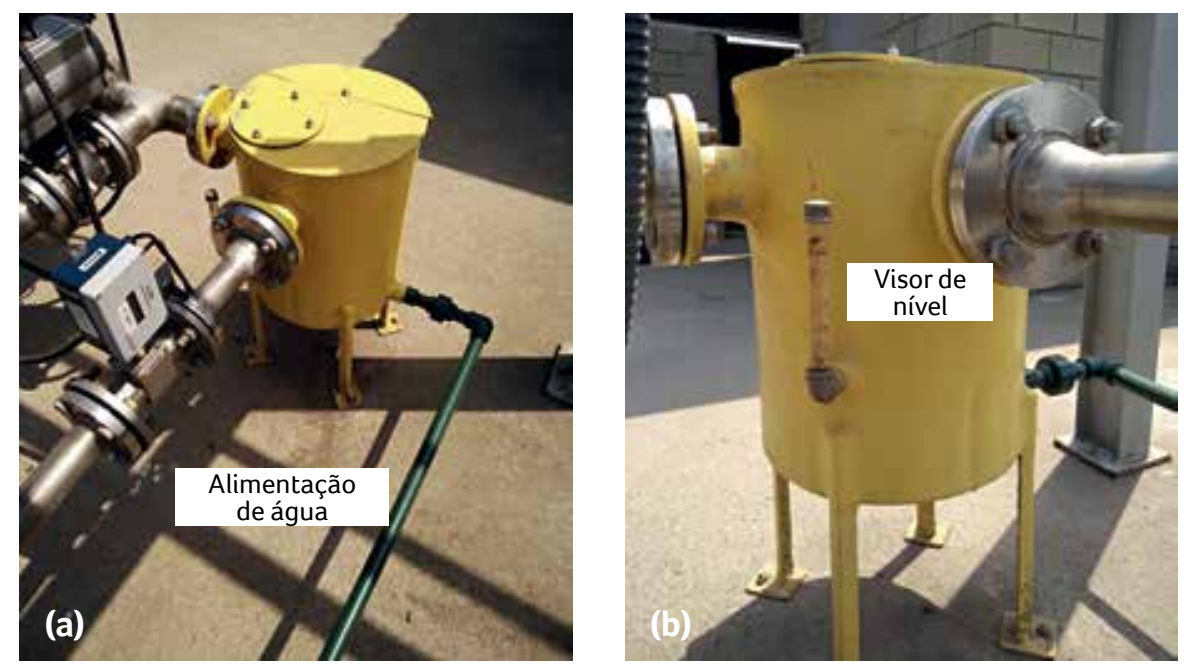

Figura 16 - Selo hídrico utilizado para controle de pressão e nível de escuma: a) vista geral da instalação;

b) detalhe do visor de nível.

\subsubsection{Separador trifásico modular Étsus-1000}

O separador trifásico modular Étsus-1000 (Figura

17) trata-se de produto em fase final de desenvolvimento, fruto de parceria firmada entre a UFMG, por meio do Instituto Nacional de Ciência e Tecnologia em Estações de Tratamento de Esgoto Susten- táveis (INCT ETEs Sustentáveis), com companhias estaduais de saneamento e empresas fabricantes de peças em fibra de vidro. Esse produto, confeccionado em plástico reforçado com fibra de vidro (PRFV), busca contribuir para a solução de diversos problemas operacionais de reatores UASB, quais 
sejam: i) o adequado gerenciamento de escuma; ii) a coleta eficiente do biogás, sem perdas por vazamentos; iii) a adequada coleta do efluente líquido tratado, evitando o desprendimento de gases residuais e a ocorrência de curtos-circuitos hidráulicos. As principais vantagens associadas ao produto são:

- Estrutura modular de separação trifásica que incorpora aspectos de leveza, resistência, estanqueidade e facilidade de transporte e instalação.
- Incorporação de sistema de remoção da escuma que se acumula no interior do separador trifásico, contribuindo diretamente para a melhoria de aspectos operacionais dos reatores UASB e de redução/eliminação de emissões odorantes e de perdas de biogás.

- Incorporação de sistema de coleta de efluente acoplado ao corpo do separador trifásico, com dispositivo de verificação de nível.
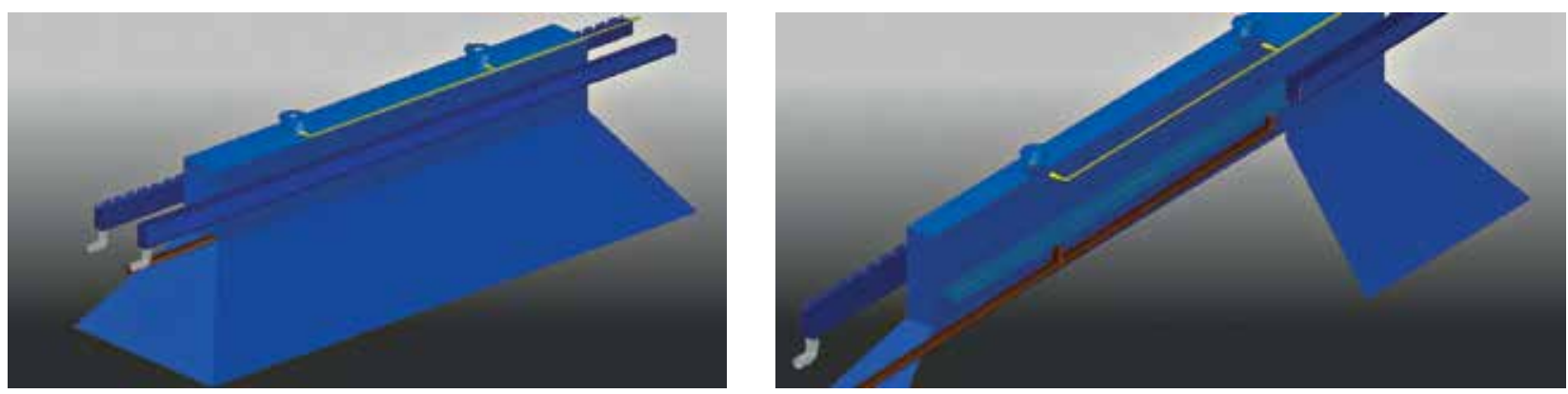

Figura 17 - Perspectiva esquemática do separador trifásico modular - Étsus 1000.

\subsection{Gerenciamento e destinação final}

Após a remoção da escuma dos reatores UASB é de extrema importância o adequado gerenciamento e destinação final deste subproduto. No Brasil, algumas ETEs têm considerado os leitos de secagem como uma etapa importante do gerenciamento. Entretanto, é necessária a inclusão de uma etapa de peneiramento, a fim de separar a elevada quantidade de material grosseiro presente na escuma da fração peneirada. O material retido na peneira deve ser encaminhado para disposição final em aterro sanitário e a fração peneirada deve ser encaminhada para desaguamento em leitos de secagem.

Adicionalmente, em função dos elevados volumes de líquido descartados juntamente com a escuma, a fração peneirada pode ser direcionada a um tanque de adensamento com intuito de separar a escuma em três fases: i) fração sobrenadante; ii) fração clarificada; e iii) fração sedimentada. Pesquisa realizada em um sistema piloto de adensamento indicou que $5 \%$ da escuma peneirada correspondeu à fração sobrenadante, 89\% à fração clarificada e $6 \%$ à fração sedimentada. A caracterização da fração clarificada apresentou concentrações medianas de ST, DQQO, DBO e óleos e graxas dentro das faixas usuais para o esgoto bruto, indicando, portanto, que essa fração pode ser retornada ao inicio do sistema de tratamento, sem prejuízos para o funcionamento e eficiência das unidades. Nesse sentido, a previsão de um tanque de adensamento para recebimento da fração peneirada da escuma é de grande importância, a fim de possibilitar a separação da fração clarificada, de grande volume, para retorno ao tratamento da fase líquida. Com isso, apenas as frações sobrenadante e sedimentada são encaminhadas para desaguamento em leitos de secagem, em conjunto ou em separado. Assim, como o volume dessas duas frações correspondeu a um pouco mais que $10 \%$ do volume total peneirado, a inclusão da etapa de adensamento, antes do desaguamento em leitos de se- 
cagem, contribui para uma redução substancial da área dessas unidades (DÍAZ FLÓREZ, 2016).

Dessa forma, os projetos mais recentes têm preconizado que a escuma (fluida) removida de reatores UASB seja encaminhada para uma unidade de peneiramento e, em sequência, para uma unidade de adensamento, conforme descrito a seguir:

i) a unidade de peneiramento (\# 1,0 mm) possibilita a separação do material grosseiro (detritos) contido na escuma (Figura 18a), para posterior disposição final em aterro sanitário;

ii) a unidade de adensamento, localizada após a unidade de peneiramento, possibilita separação da fração clarificada das demais frações (sobrenadante e sedimentada), com o retorno da fração clarificada para a unidade de tratamento preliminar, ou para o próprio reator UASB, e as demais frações para os leitos de secagem (Figura 18b).
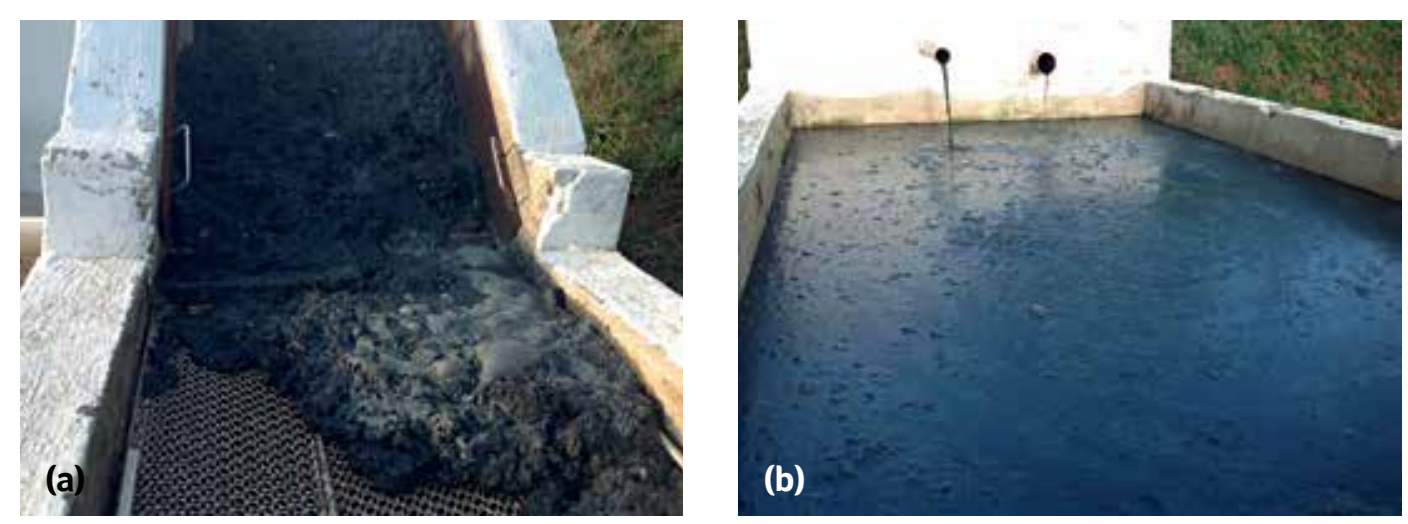

Figura 18 - a) Fração grosseira de escuma retida em unidade de peneiramento; b) fração sobrenadante de escuma enviada para leito de secagem.

\section{GERENCIAMENTO INTEGRADO DE LODO E ESCUMA}

A adoção dos aprimoramentos apresentados nessa NT e o gerenciamento integrado dos subprodutos sólidos - lodo e escuma - são de fundamental importância para garantir a eficiência do sistema de tratamento. Na Figura 19 são apresentadas alternativas para o gerenciamento integrado de lodo e escuma (e biogás), as quais podem trazer importantes benefícios para as ETEs. Destaque para as seguintes possibilidades principais:

- Uso do biogás para secagem térmica do lodo (e da escuma).
- Envio do lodo (e da escuma) para tanques de adensamento, de modo a possibilitar a separação e retorno do excesso de água para a unidade de tratamento preliminar, ou para o próprio reator UASB.

- Higienização do lodo (e da escuma) em leitos de secagem (aquecidos com biogás), em secadores solares ou em secadores térmicos, os quais podem propiciar que o material desaguado seja aproveitado em atividades agrossilvipastoris ou em unidades de aproveitamento energético, ao invés de ser disposto em aterros sanitários. 


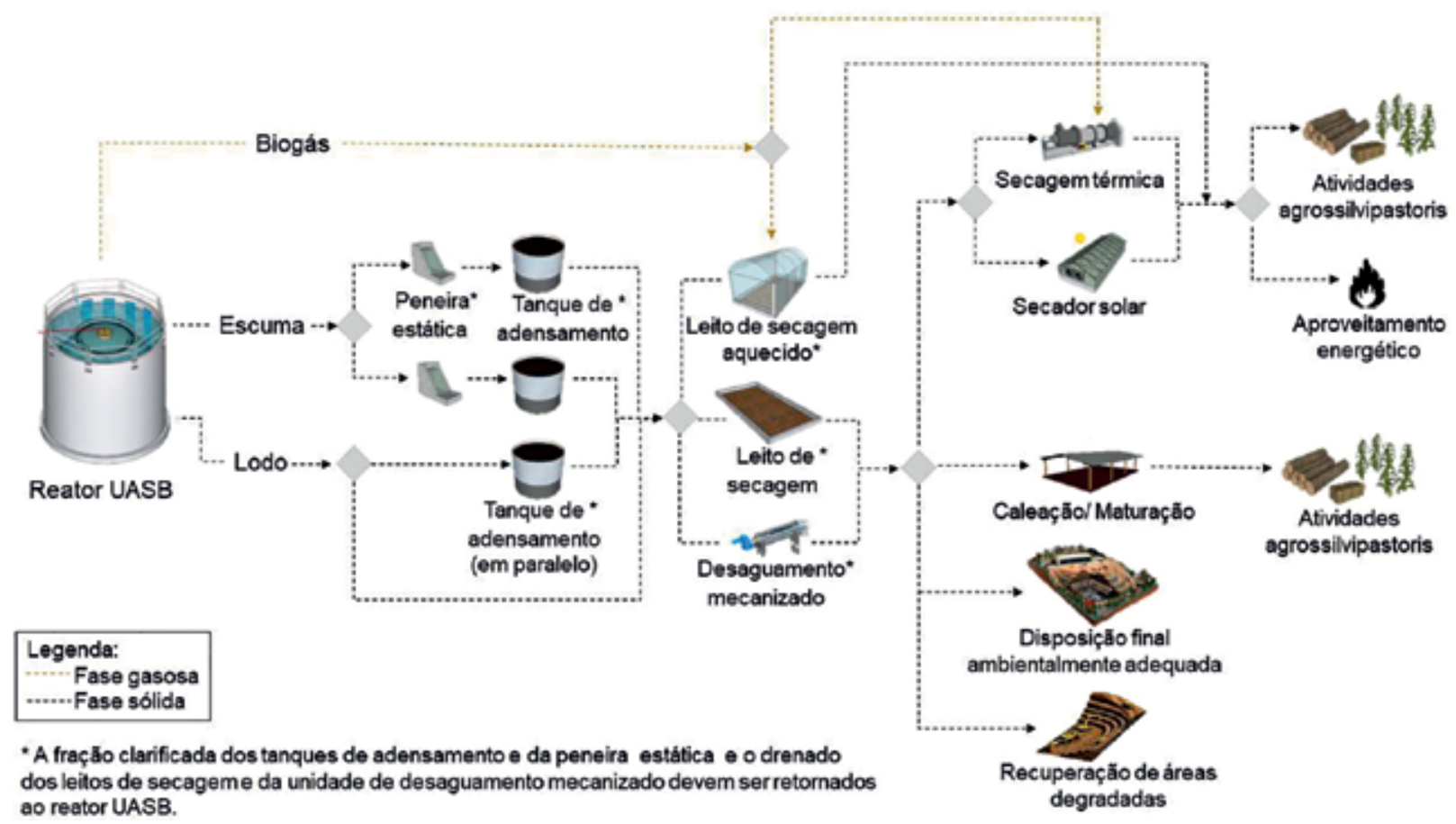

Figura 19 - Alternativas para o gerenciamento integrado de lodo e escuma.

\section{AGRADECIMENTOS}

Os autores agradecem as contribuições de Izabel Cristina Chiodi de Freitas e Ayana Lemos Emrich na elaboração dessa NT e as empresas Biofibra e Fibrasa pela parceria no desenvolvimento do separador trifásico Étsus-1000. Agradecem ainda o apoio recebido do Conselho Nacional de Desenvolvimento Científico e Tecnológico - CNPq, da Coordenação de Aperfeiçoamento de Pessoal de Nível Superior - CAPES, da Fundação de Amparo à Pesquisa do Estado de Minas Gerais - FAPEMIG e do Instituto Nacional de Ciência e Tecnologia em Estações Sustentáveis de Tratamento de Esgoto INCT ETEs Sustentáveis.

Este trabalho faz parte da série de publicações do INCT ETEs Sustentáveis.

\section{REFERÊNCIAS BIBLIOGRÁFICAS}

ABNT - Associação Brasileira de Normas Técnicas. NBR 12209: Elaboração de projetos hidráulico-sanitários de estações de tratamento de esgotos sanitários. $2^{\mathrm{a}}$ ed. Rio de Janeiro, 2011. 57 p.

ALMEIDA, P. G. S., BRESSANI RIBEIRO, T., SILVA, B. S., AZEVEDO, L. S., CHERNICHARO, C. A. L. Contribuição para o aprimoramento de projeto, construção e operação de reatores UASB aplicados ao tratamento de esgoto sanitário - Parte 6: Qualidade do Efluente. Revista DAE - edição especial, v. 66, n. 214, p. 90-108, 2018.

BRESSANI-RIBEIRO, T., LOBATO, L.C.S., MELO, V.R., PEGORINI, E., NONATO, S., CHERNICHARO, C.A.L. Contribuição para o aprimoramento de projeto, construção e operação de reatores UASB aplicados ao tratamento de esgoto sanitário - Parte 2: Tratamento Preliminar. Revista DAE - edição especial, v. 66, n. 214, p. 17-29, 2018. CHERNICHARO, C. A. L. Reatores anaeróbios. $2^{\text {a }}$ ed. Belo Horizonte: Departamento de Engenharia Sanitária e Ambiental. Universidade Federal de Minas Gerais, 2007. 380 p. (Princípios do tratamento biológico de águas residuárias, v.5). 
CHERNICHARO, C. A. L., BRESSANI-RIBEIRO, T., PEGORINI, E., POSSETTI, G. R. C., MIKI, M. K., NONATO, S. Contribuição para o aprimoramento de projeto, construção e operação de reatores UASB aplicados ao tratamento de esgoto sanitário - Parte 1: Tópicos de Interesse. Revista DAE - edição especial, v. 66, n. 214, p. 5-16, 2018.

DÍAZ FLÓREZ, C. A. Avaliação de protocolos de descarte e desidratação da escuma acumulada no interior de separadores trifásicos de reatores UASB. 2016, 83 p. Dissertação (Mestrado em Saneamento, Meio Ambiente e Recursos Hídricos, Escola de Engenharia). Escola de Engenharia, Universidade Federal de Minas Gerais, Belo Horizonte, 2016.

LEITÃO, R. C., SANTAELLLA, S. T., van HAANDEL, A. C., ZEEMAN, G., LETTINGA, G. The effect of operational conditions on the hydrodynamic characteristics of the sludge bed in UASB reactors. In: $12^{\text {th }}$ World Congress on Anaerobic Digestion, 2010, Guadalajara, México. Proceedings... Guadalajara, México: International Water Association - IWA, 2010

LETTINGA, G., HULSHOFF POL, L.W. UASB - Process design for various types of wastewaters. Water Science \& Technology, v. 24, n. 8, p. 87-107, 1991.

MIKI, M. K. Dilemas do UASB. Revista DAE, v.183, n. 1504, p. 2537, 2010

RAMOS, R. A. Avaliação da influência da operação de descarte de lodo no desempenho de reatores UASB em estações de tratamento de esgotos no Distrito Federal. 2008, 135 p. Dissertação (Mestrado em Tecnologia Ambiental e Recursos Hídricos). Universidade de Brasília, 2008.
ROSA, A.P., LOBATO, L.C.S., CHERNICHARO, C.A.L., MARTINS, D. C. R. B., MACIEL, F. M., BORGES, J. M. Improving performance and operational control of UASB reactors via proper sludge and scum discharge routines. Water Practice \& Technology, v. 7, n. 3, p. $1-11,2012$

SANTOS, A. Remoção, tratamento e valoração de escuma proveniente de reatores UASB aplicados ao tratamento de esgoto doméstico. 2014. 115 f. Tese (Doutorado em Saneamento, Meio Ambiente e Recursos Hídricos) - Escola de Engenharia. Universidade Federal de Minas Gerais, Belo Horizonte, 2014

SATO, N., OKUBO, T., OHASHI, A. \& HARADA, H. Prospects for a self-sustainable sewage treatment system: case study on full-scale UASB system in India's Yamuna River Basin. J. Environ. Manage. v. 80, n.3, p. 198-207, 2006.

SOUZA, C. L., SILVA, S. Q., AQUUINO, S. F. \& CHERNICHARO, C. A. L. Production and characterization of scum and its role in odour control in UASB reactors treating domestic wastewater. In: $4^{\text {th }}$ World Water Congress, Beijing, China. Proceedings...Beijing, China: International Water Association - IWA, 2006.

van LIER, J. B., VASHI, A., van der LUBBE, J., HEFFERNAN, B. Anaerobic sewage treatment using UASB reactors: Engineering and operational aspects. In: Fang, H.H.P. (Editor) Environmental anaerobic technology: applications and new developments. Imperial College Press -London-UK. p. 59-87, 2011. 